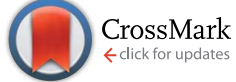

Cite this: RSC Adv., 2015, 5, 11058

Received 28th November 2014 Accepted 7th January 2015

DOI: $10.1039 / c 4 r a 15456 h$

www.rsc.org/advances

\section{Graphene boosts thermoelectric performance of a Zintl phase compound $\dagger$}

\author{
A. Bhardwaj, A. K. Shukla, S. R. Dhakate and D. K. Misra*
}

The concept of nanocomposites derived by incorporating a second minor phase in bulk thermoelectric materials has established itself as an effective paradigm for optimizing high thermoelectric performance. In this work, this paradigm is for the first time extended to bulk Zintl phase $\mathrm{Mg}_{3} \mathrm{Sb}_{2}$ and its isoelectronically $\mathrm{Bi}$-doped derivative $\mathrm{Mg}_{3} \mathrm{Sb}_{1.8} \mathrm{Bi}_{0.2}$ system. Herein, we report the synthesis, microstructural details, electronic structure and thermoelectric properties of $\left(\mathrm{Mg}_{3} \mathrm{Sb}_{2}, \mathrm{Mg}_{3} \mathrm{Sb}_{1.8} \mathrm{Bi}_{0.2}\right)$ / graphene nanosheet (GNS) nanocomposites with different mass ratios. Field emission scanning electron microscopy (FE-SEM) and transmission electron microscopy (TEM) investigation reveals that $\mathrm{Mg}_{3} \mathrm{Sb}_{2}$ nanoparticles are homogenously anchored on the surface of GNS. We demonstrate that $\mathrm{Mg}_{3} \mathrm{Sb}_{2}$-based materials incorporated with a small content of graphene outperform optimally, resulting in potential ptype thermoelectric materials. The present nanocomposite additive of GNS deriving such a novel nanocomposite of $\left(\mathrm{Mg}_{3} \mathrm{Sb}_{2}, \mathrm{Mg}_{3} \mathrm{Sb}_{1.8} \mathrm{Bi}_{0.2}\right) / \mathrm{GNS}$, enhances the electrical conductivity significantly, thereby resulting in a substantially large increase in the power factor. The enhanced electrical conductivity of these nanocomposites is attributed to the increase in the carrier concentration and high carrier mobility owing to the ultra high mobility of graphene. X-ray photoelectron spectroscopy (XPS) core level spectra confirm weak bonding between GNS and $\mathrm{Mg}_{3} \mathrm{Sb}_{2}$. Increase in carrier concentration is reflected in XPS valence band spectra and change in spectral weight near valence band maxima is indicative of increased electrical conductivity in the nanocomposite material. The thermal conductivity of these nanocomposites is noted to be reduced at high temperature. These favorable conditions lead to enhanced thermoelectric figure-of-merit $(Z T) \approx 0.71$ at $773 \mathrm{~K}$ for $\mathrm{Mg}_{3} \mathrm{Sb}_{2} / \mathrm{GNS}$ and a $Z T \approx 1.35$ at $773 \mathrm{~K}$ for $\mathrm{Mg}_{3} \mathrm{Sb}_{1.8} \mathrm{Bi}_{0.2} / \mathrm{GNS}$ nanocomposites with the mass ratio of $80: 1$ which are $\sim 170 \%$ and $\sim 125 \%$ higher values compared to bare $\mathrm{Mg}_{3} \mathrm{Sb}_{2}$ and bare $\mathrm{Mg}_{3} \mathrm{Sb}_{1.8} \mathrm{Bi}_{0.2}$ respectively. We strongly believe that the present novel strategy of fabricating such a nanocomposite of a Zintl compound by utilizing GNS as a nanocomposite additive, may provide an emerging path for improving thermoelectric properties of various Zintl phase compounds.

\section{Introduction}

The prospects of climate change, eventual fossil fuel depletion and increasing $\mathrm{CO}_{2}$ content, revive tremendous interest in exploring thermoelectric materials with high efficiency by which a heat-to-electricity energy conversion could be accomplished. The efficiency of thermoelectric energy conversion depends on a material's dimensionless figure of merit $Z T$, defined as $Z T=\frac{\alpha^{2} \sigma T_{1}}{\kappa}$ where $\sigma$ is the electrical conductivity, $\alpha$, the Seebeck coefficient, $\kappa$, the thermal conductivity and $T$, the absolute temperature. An efficient thermoelectric material requires high $\alpha$ and $\sigma$ and hence a large power factor $\left(\mathrm{PF}=\alpha^{2} \sigma\right)$

CSIR-Network of Institutes for Solar Energy, Materials Physics \& Engineering Division, CSIR-National Physical Laboratory, Dr K. S. Krishnan Marg, New Delhi-110012, India. E-mail: misradk@nplindia.org; dakkmisra@gmail.com

$\dagger$ Electronic supplementary information (ESI) available. See DOI: $10.1039 / \mathrm{c} 4 \mathrm{ra} 15456 \mathrm{~h}$ as well as a low value of $\kappa$. A large value for the power factor of a material requires it to possess a large effective mass $\left(m^{*}\right)$ and high carrier mobility $\mu .^{2}$

Several strategies such as doping, ${ }^{3-6}$ solid solution alloying, ${ }^{7-10}$ and nanostructuring/nanocomposite, ${ }^{11-16}$ have been utilized to modify the structure, hence improving the thermoelectric properties. Such microstructural modifications lead to several important mechanisms e.g. shifting of the Fermi level, creating local band resonant states, facilitating the convergence of valence band or conduction bands, inducing high effective mass and interface energy filtering effect which are usually helpful to improve the electronic properties. ${ }^{17-21}$ Apart from the improvement of electronic properties, these strategies are also helpful to impede the propagation of thermal phonons by enhancing interface phonon scattering together with creating local structural disorder to increase the frequency of phonon scattering processes as well. Based on these strategies many materials such as $\mathrm{Bi}_{2} \mathrm{Te}_{3},{ }^{22-26} \mathrm{LAST},{ }^{27} \mathrm{TAGS},{ }^{28} \mathrm{PbTe}^{29,30} \mathrm{SiGe}^{31,32}$ 
and Zintl phase compounds ${ }^{\mathbf{8}, 33-49}$ have been widely investigated and high $Z T$ had been optimized.

All of the above strategies were mainly focused on increasing the $m^{*}$ and reducing the lattice thermal conductivity. Unfortunately, the possibility to improve the carrier mobility $(\mu)$ was missed by the researchers which had been largely the victim of such structural modifications and hence needs to be focused for further improvement in thermoelectric properties.

Along the prospective to improve the electrical properties, graphene with high carrier mobility $(\mu)$ can be utilized as composite additive for thermoelectric matrix in order to improve the thermoelectric performance of resulting nanocomposites. Graphene has become one of the most exciting material due to its unique electrical, optical, opto-electronics, and mechanical properties. Graphene, particularly, with its two dimension (2D) single layer structure and with $\mathrm{sp}^{2}$ hybridization exhibits several intriguing properties e.g. high electrical conductivity $\left(\approx 6000 \mathrm{~S} \mathrm{~cm}^{-1}\right)$ high carrier mobility, $\left(\approx 20000 \mathrm{~cm}^{2} \mathrm{~V}^{-1} \mathrm{~s}^{-1}\right)$ high specific surface area, $\left(\approx 2600 \mathrm{~m}^{2} \mathrm{~g}^{-1}\right)$ and excellent mechanical properties (mechanical stiffness $\approx 130 \mathrm{GPa}$ ). ${ }^{50-56}$ These exciting features of graphene make them a promising candidate for developing various kinds of functional nanocomposites with potential applications in super capacitors, ${ }^{57,58}$ electric circuit, $^{59}$ fuel cell, ${ }^{60}$ conductive polymers ${ }^{61}$ and biosensors. ${ }^{62}$ Interestingly, it has been argued by some researchers that the addition of graphene in Ag-matrix could increase the electrical conductivity by introducing large number of electronic transmission channels. ${ }^{63}$ However, till date; only few reports ${ }^{64-68}$ are available where graphene has been utilized as inclusions in thermoelectric materials for optimizing their high $Z T$.

On the other hand, Zintl phases are considered as an unique class of thermoelectric materials due to their unusual structural characteristics which lead to an important behavior of phononglass electron-crystal (PGEC) ${ }^{\mathbf{6 9}}$ needed for a materials to achieve high $Z T .^{70,71}$ They combine distinct regions of covalent bonding ideal for electron-crystal properties and ionically bond cations that can easily be substituted for precise tuning of electronic properties, leading to the desired "electron crystal" behavior. $^{\text {70,72 }}$ The complex structures create phonon-glass properties resulting in low lattice thermal conductivity, making many Zintl compounds a natural "phonon glass". ${ }^{73,74}$ As a consequences of these behaviors, a varieties of Zintl phase compounds such as $\mathrm{Yb}_{14} \mathrm{MnSb}_{11},{ }^{35} \mathrm{Zn}_{4} \mathrm{Sb}_{3},{ }^{36} \mathrm{Yb}_{9} \mathrm{Mn}_{4.2} \mathrm{Sb}_{9},{ }^{37}$ filled skutterudites, ${ }^{38,39}$ clathrates, ${ }^{40,41}(\mathrm{Yb}, \mathrm{Ba}) \mathrm{Zn}_{2} \mathrm{Sb}_{2},{ }^{42,43} \mathrm{YbCd}_{2} \mathrm{Sb}_{2},{ }^{44}$ $\mathrm{BaGa}_{2} \mathrm{Sb}_{2},{ }^{45}\left(\mathrm{Eu}_{5}, \mathrm{Yb}_{5}\right) \mathrm{In}_{2} \mathrm{Sb}_{6},{ }^{46,47} \mathrm{EuZn}_{2} \mathrm{Sb}_{2},{ }^{48} \mathrm{AZn}_{2} \mathrm{Sb}_{2}{ }^{49}$ etc. with high $Z T$ have been developed. However, the use of expensive rare earth elements and toxic chalcogenides in majority of Zintl phase materials limits their use in large scale industrial application for power generation.

$\mathrm{Mg}_{3} \mathrm{Sb}_{2}$ is a unique Zintl phase compound constituted with cheap, rare earth free and non-toxic constituents which crystallizes in cubic bixbyite ( $\alpha$-phase) as well as in hexagonal structures ( $\beta$-phase).$^{75}$ The $\alpha$-phase cubic bixbyite structure is $\mathrm{La}_{2} \mathrm{O}_{3}$-type which is the high temperature phase, structured with 80 atoms per unit cell with $48 \mathrm{Mg}$ and $32 \mathrm{Sb}$ atoms. At low temperature, below $\sim 1200 \mathrm{~K}, \mathrm{Mg}_{3} \mathrm{Sb}_{2}$ crystallizes to $\mathrm{Mn}_{2} \mathrm{O}_{3}$ type $\beta$-phase with unit cell composed of 5 atoms ( $3 \mathrm{Mg}$ and $2 \mathrm{Sb}$ ). The $\beta$-phase hexagonal structure (space group $P \overline{3} m 1$; no. 164) which is under our investigation, consists of two inequivalent $\mathrm{Mg}$ sites, denoted as $\mathrm{Mg}$ (I) and $\mathrm{Mg}$ (II) which are covalent and ionic in nature respectively. Thus, the bonding characteristic of $\mathrm{Mg}_{3} \mathrm{Sb}_{2}$ is in between metallic and ionic. ${ }^{76,77}$ Similar to the structure of $\mathrm{CaAl}_{2} \mathrm{Si}_{2}$, the stoichiometric $\mathrm{Mg}_{3} \mathrm{Sb}_{2}$ compound consists of interspersed $\mathrm{Mg}_{2} \mathrm{Sb}_{2}{ }^{2-}$ layers (the tetrahedral position in the lattice) and $\mathrm{Mg}^{2+}$ cation layers (the octahedral position in the lattice). ${ }^{78}$ The $\beta-\mathrm{Mg}_{3} \mathrm{Sb}_{2}$ phase exhibits a band gap of $0.4 \mathrm{eV}$. It has a fairly large effective mass, high thermo power, low thermal conductivity but unfortunately a poor electrical conductivity which is largely the reason for the low thermoelectric performance. In our earlier report, ${ }^{8}$ we demonstrated the increase in $Z T$ in $\mathrm{Mg}_{3} \mathrm{Sb}_{2-x} \mathrm{Bi}_{x}(0 \leq x \leq 0.4)$ alloys by isoelectronic substitution of $\mathrm{Bi}^{3-}$ on $\mathrm{Sb}^{3-}$ site. The enhancement in $Z T$ was attributed to the increased Seebeck coefficient and reduced thermal conductivity. Despite the large increase in the Seebeck coefficient and significant reduction in the thermal conductivity, there was no significant improvement in the electrical conductivity resulting to only moderate improvement in $Z T$ of these materials. ${ }^{8}$

In this work, we have adopted nanocomposite approach by incorporating graphene nanosheet (GNS), in $\mathrm{Mg}_{3} \mathrm{Sb}_{2}$ (with high $m^{*}$ and low $\kappa$ ) for further improving the $Z T$ of this potential thermoelectric material. Combination of higher $\mu$ and lower $\kappa$ would be important to attain superior thermoelectric performance. Several exciting features of graphene namely high electrical conductivity and a large carrier mobility perceived with potential $\mathrm{Mg}_{3} \mathrm{Sb}_{2}$ thermoelectric materials may be expected to result in large increase in the electrical conductivity with less effect on the Seebeck coefficient of $\mathrm{Mg}_{3} \mathrm{Sb}_{2} / \mathrm{GNS}$ nanocomposite which is expected to improve the thermoelectric properties.

Herein, we have synthesized $\mathrm{Mg}_{3} \mathrm{Sb}_{2} /$ GNS nanocomposite by incorporating GNS in different weight fractions in a precursor of pre-synthesized $\mathrm{Mg}_{3} \mathrm{Sb}_{2}$ host compound via wet ball milling route followed by rapid-heating using spark plasma sintering (SPS). An enhanced thermoelectric figure-of-merit $(Z T) \approx 0.71$ at $773 \mathrm{~K}$ of $\mathrm{Mg}_{3} \mathrm{Sb}_{2} / \mathrm{GNS}$ with mass ratio of $80: 1$ for nanocomposite was realized which is about $170 \%$ higher than that of its bulk counterpart $\mathrm{Mg}_{3} \mathrm{Sb}_{2}$ compound. Further, the same strategy of fabricating the nanocomposite by incorporating GNS with the same mass ratio of $80: 1$ was demonstrated in $\mathrm{Mg}_{3} \mathrm{Sb}_{1.8} \mathrm{Bi}_{0.2}$ and thermoelectric properties were investigated. Interestingly, GNS addition consistently enhances the electrical conductivity ( $>650 \%)$ which in turn increases the power factor $(\sim 90 \%)$ and thereby resulting to a large increase in $Z T \approx 1.35$ at $773 \mathrm{~K}$ of $\mathrm{Mg}_{3} \mathrm{Sb}_{1.8} \mathrm{Bi}_{0.2} / \mathrm{GNS}$ nanocomposite with mass ratio of $80: 1$. To the best of our knowledge, such strategy of incorporating GNS in Zintl phase thermoelectric matrix for achieving high thermoelectric figure of merit has not been reported so far.

\section{Experimental detail}

\subsection{Materials processing and densification}

Stoichiometry of $\mathrm{Mg}_{3} \mathrm{Sb}_{2}$ and $\mathrm{Mg}_{3} \mathrm{Sb}_{1.8} \mathrm{Bi}_{0.2}$ with high purity elements magnesium (Mg; 99.99\%, Alfa Aesar), antimony (Sb; 
99.99\%, Alfa Aesar), and bismuth (Bi; 99.99\%, Alfa Aesar), were blended by mechanical milling and subsequently grounded in an agate mortar. The blended powders were then subjected to spark plasma sintering (SPS) at a temperature and pressure of $1073 \mathrm{~K}$ and $50 \mathrm{MPa}$, respectively, for a holding time of $10 \mathrm{~min}$. Pellets of $12.7 \mathrm{~mm}$ in diameter were obtained. The strategy to following the SPS synthesis route is to melt the stoichiometric at high temperature and cool it fast to form nanosized grains of single $\mathrm{Mg}_{3} \mathrm{Sb}_{2}$ composition phase.

The graphite intercalated compound was thermally expanded to get fully thermally expanded graphite. ${ }^{79}$ The thermally expanded graphite and organic solvent dimethyl formamide (DMF) was taken in the ratio of $5.0 \mathrm{mg} \mathrm{ml}^{-1}$ and was placed into a stainless steel jar containing stainless steel balls of diameter 5 $\mathrm{mm}$. The ratio of expanded graphite to stainless steel ball was $1: 100$ by weight. The milling was carried out in an ambient temperature. The mixture was milled by planetary ball milling for 15 hours at a rotation speed $300 \mathrm{rpm}$. The resulting solution was dried and few layer graphene (FLG) nano sheets (GNS) in the form of powder were obtained. ${ }^{80}$ The FLG nano sheets derived from the ball milling of expanded graphite in organic solvent was used as conducting reinforcement in the pre-synthesized precursor of $\mathrm{Mg}_{3} \mathrm{Sb}_{2}$. Before mixing of graphene in $\mathrm{Mg}_{3} \mathrm{Sb}_{2}$ matrix, it was ball milled for two hours to disperse the GNS properly. The different mass ratio $100: 1,80: 1,60: 1$ and $40: 1$ of $\mathrm{Mg}_{3} \mathrm{Sb}_{2} / \mathrm{GNS}$ were mixed in wet ball milling in organic solvent and subsequently the organic solvent was evaporated completely. The resulting mixtures of $\mathrm{Mg}_{3} \mathrm{Sb}_{2}$ and GNS were subjected to SPS at temperature of $600{ }^{\circ} \mathrm{C}$ and pressure of $50 \mathrm{MPa}$ in order to have a pellet of high density nanocomposite materials. The similar synthesis procedure was followed for fabricating $\mathrm{Mg}_{3} \mathrm{Sb}_{1.8} \mathrm{Bi}_{0.2} /$ GNS nanocomposite with mass ratio of $80: 1$.

\subsection{Structural characterization}

The gross structural characterization of $\mathrm{Mg}_{3} \mathrm{Sb}_{2} / \mathrm{GNS}$ nanocomposite was carried out by powder X-ray diffractometer (Rigaku Mini Flex II) in reflection $\theta-2 \theta$ geometry, with position sensitive detector (Ultafast D Tex), operating at $30 \mathrm{kV}$ and 20 $\mathrm{mA}$, using a graphite monochromator and $\mathrm{CuK}_{\alpha}$ radiation with wavelength $\lambda \approx 1.5406 \AA$ along with $\mathrm{CuK}_{\alpha 2}$ filter and rotating anode equipped with powder $2 \theta$ diffractometer ranging from 20 to 80 degrees. The experimental conditions and parameters such as sample size, power ratings of X-ray tube $(30 \mathrm{kV}, 20 \mathrm{~mA})$ and other diffractometer parameters such as scan speed, counting steps etc. were kept constant for all diffraction experiments.

The microstructure investigation of host $\mathrm{Mg}_{3} \mathrm{Sb}_{2}$ Zintl compound and $\mathrm{Mg}_{3} \mathrm{Sb}_{2} / \mathrm{GNS}$ nanocomposite after SPSed was carried out by field emission scanning electron microscopy (FESEM; Model: SUPRA40 VP, operating at $30 \mathrm{kV}$ ) and HRTEM (Modell: Technai $\mathrm{G}^{2} \mathrm{~F}^{30}$;STWIN) operating at $300 \mathrm{kV}$. The elemental analysis of the samples was performed using energy dispersive spectroscopy (EDS) attached to the FE-SEM. The detail of TEM specimen preparation of $\mathrm{Mg}_{3} \mathrm{Sb}_{2}$ has been described elsewhere ${ }^{8}$ and same procedure has been followed for present nanocomposites.

\subsection{Thermoelectric properties}

Thermal diffusivity of $\left(\mathrm{Mg}_{3} \mathrm{Sb}_{2}, \mathrm{Mg}_{3} \mathrm{Sb}_{1.8} \mathrm{Bi}_{0.2}\right) / \mathrm{GNS}$ nanocomposite samples were measured by using a laser flash system (Lineseis, LFA 1000) on disk-shaped thin specimens with approximate thickness of $1.5 \mathrm{~mm}$ and diameter of $12.7 \mathrm{~mm}$. The disc specimens used for thermal diffusivity were sprayed with a layer of graphite in order to minimize errors due to emissivity. Specific heat was determined by a differential scanning calorimetry (DSC) instrument (822e Mettler Toledo). The thermal conductivity of nanocomposites was calculated using the relation, $\kappa=d \times C_{\mathrm{p}} \times \rho$ where $d$ is the thermal diffusivity, $\rho$ the geometrical pellet density and $C_{\mathrm{p}}$ the heat capacity. The Seebeck coefficients and the resistivity were measured simultaneously employing commercial equipment (ULVAC, ZEM3) over the temperature range of $300 \mathrm{~K}$ to $773 \mathrm{~K}$ on samples of polished bars of about $3 \times 1.5 \times 10 \mathrm{~mm}^{3}$.

\subsection{Raman spectroscopy}

The graphene derived from expanded graphite and $\mathrm{Mg}_{3} \mathrm{Sb}_{2} / \mathrm{GNS}$ nanocomposites was characterized by Raman spectrometer (Reninshaw, micro Raman model in Via Reflex) with $514 \mathrm{~nm}$ laser excitation and notch filter cutting at $50 \mathrm{~cm}^{-1}$ at room temperature. The Raman spectra was recorded from $50 \mathrm{~cm}^{-1}$ to $3000 \mathrm{~cm}^{-1}$ with $5 \mathrm{~mW}$ laser power and $10 \mathrm{~s}$ exposure time. The $50 \times$ microscope objective was used and the spot size of the laser was $1-2 \mu \mathrm{m}$.

\subsection{Hall measurement}

Room temperature Hall effect was carried out using the van der Pauw method. The Hall coefficient was determined using an a.c. power supply of $29 \mathrm{~Hz}$ frequency and magnetic induction of $0.9 \mathrm{~T}$. The Hall carrier concentration $n_{\mathrm{H}}$ was calculated via $n_{\mathrm{H}}=1 / e R_{\mathrm{H}}$, where $R_{\mathrm{H}}$ is the Hall coefficient and $e$ is the electron charge. The Hall mobility $\mu_{\mathrm{H}}$ was calculated by a relation $\mu_{\mathrm{H}}=\sigma / n_{\mathrm{H}} e$, where $\sigma$ is the electrical conductivity.

\subsection{Thermal expansion measurement}

The coefficient of thermal expansion (CTE) of GNS, $\mathrm{Mg}_{3} \mathrm{Sb}_{2}$, $\mathrm{Mg}_{3} \mathrm{Sb}_{2} / \mathrm{GNS}$ nanocomposites was measured by thermomechanical analyzer (TMA-Q400, TA Instruments) in Nitrogen atmosphere in the temperature range $50-500{ }^{\circ} \mathrm{C} @ 10{ }^{\circ} \mathrm{C} \mathrm{min}^{-1}$.

\subsection{X-ray photo electron spectroscopy (XPS)}

XPS experiments were carried out in a multi-chamber equipped with an Omicron EA 125 electron energy analyzer and monochromated $\mathrm{Al} \mathrm{K}_{\alpha} \mathrm{X}$-ray source with ultra high vacuum (UHV) surface science system maintained at the base pressure of $10^{-10}$ mbar range. All binding energies have been referenced to the Fermi edge of an $\mathrm{Ar}^{+}$sputtered clean polycrystalline $\mathrm{Ag}$ sample. The XPS data has been collected using $20 \mathrm{eV}$ analyzer pass energy which results in an overall energy resolution of $0.37 \mathrm{eV}$ determined from the Fermi edge broadening of polycrystalline Ag. The composition of the samples have been determined from the normalized area under the curve of $\mathrm{Mg} 2 \mathrm{~s}$ and $\mathrm{Sb} 4 \mathrm{~d}$ core levels of $\mathrm{Mg}_{3} \mathrm{Sb}_{2}$ and $\mathrm{Mg} 2 \mathrm{~s}, \mathrm{Sb} 4 \mathrm{~d}$, and graphene core levels for 
$\mathrm{Mg}_{3} \mathrm{Sb}_{2} / \mathrm{GNS}$ nanocomposite. These spectra are recorded under similar conditions, i.e. comparable analyzer settings, X-ray source intensity and sample position. Area under the curve of each core level used in composition calculation was normalized by respective photoemission cross section, inelastic mean free path and analyzer transmission function.

\section{Results and discussion}

The X-ray diffraction (XRD) pattern of the SPSed pellets of $\mathrm{Mg}_{3} \mathrm{Sb}_{2}, \quad\left(\mathrm{Mg}_{3} \mathrm{Sb}_{2}, \quad \mathrm{Mg}_{3} \mathrm{Sb}_{1.8} \mathrm{Bi}_{0.2}\right) / \mathrm{GNS}$ nanocomposites are shown in Fig. 1(a).

In case of bare $\mathrm{Mg}_{3} \mathrm{Sb}_{2}$ compound, all the peaks are well indexed to $\beta-\mathrm{Mg}_{3} \mathrm{Sb}_{2}$ (hexagonal; space group $P \overline{3} m 1$, JCPDS no. 00-003-0375) with no detectable impurities of other phases (the inset shows the crystal structure of $\mathrm{Mg}_{3} \mathrm{Sb}_{2}$ ). On the other hand, $\mathrm{XRD}$ of all the nanocomposites reveal the presence of graphene peak (at $2 \theta \approx 26.51^{\circ}$ ) along with prominent peaks of $\beta-\mathrm{Mg}_{3} \mathrm{Sb}_{2}$. The intensity of graphene peaks increases consistently with increasing concentration of GNS in the $\mathrm{Mg}_{3} \mathrm{Sb}_{2}$. Fig. 1(b) displays TEM images of GNS revealing the GNS width to be about $\sim 260 \mathrm{~nm}$. The inset of Fig. 1(b) is XRD pattern of GNS showing peaks of graphene. No any impurity phase was detected. The HRTEM images obtained from graphene [Fig. 1(c)] clearly reveals the lattice fringes corresponding to graphene. ${ }^{\mathbf{8 1}}$

Fig. 2 shows the Raman spectra of GNS, $\mathrm{Mg}_{3} \mathrm{Sb}_{2}$ and $\mathrm{Mg}_{3} \mathrm{Sb}_{2} /$ GNS nanocomposite for mass ratio $80: 1$. The Raman spectra recorded from graphene reveals three bands at 1354, 1582 and $2723 \mathrm{~cm}^{-1}$ corresponding to the disordered (D) band, graphitic (G) band and broad 2D band respectively. The disordered (D) band is due to the $\mathrm{sp}^{3}$ bonding of carbon atoms, graphitic (G) band is due to the $\mathrm{sp}^{2}$ bonding of carbon atoms and broad $2 \mathrm{D}$ band which is the second order of the $\mathrm{D}$ peak but it is not related to defect level in the structure. The intensity ratio of $2 \mathrm{D} /$ $\mathrm{G}$ is $\sim 0.50$ which corresponds to four to five layers in the graphene. However, for the $\mathrm{Mg}_{3} \mathrm{Sb}_{2} / \mathrm{GNS}$ nanocomposite with mass

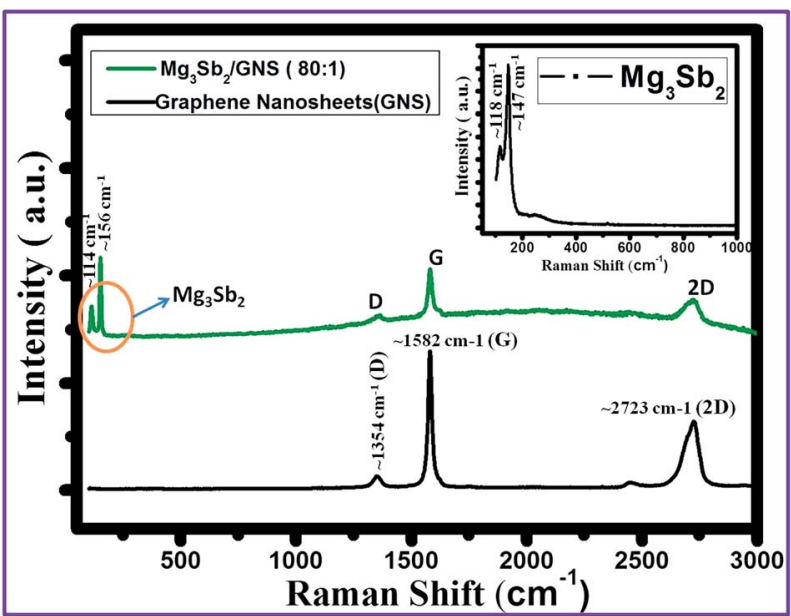

Fig. 2 The Raman spectra of graphene nanosheets (black color spectra) and $\mathrm{Mg}_{3} \mathrm{Sb}_{2} / \mathrm{GNS}$ nanocomposites for mass ratio $80: 1$ (green color spectra). Inset shows the spectra for $\mathrm{Mg}_{3} \mathrm{Sb}_{2}$.

ratio $80: 1$, same Raman shift $\mathrm{D}, \mathrm{G}$ and $2 \mathrm{D}$ peaks are appearing with $2 \mathrm{D} / \mathrm{G}$ ratio of $\sim 0.50$ together with spectra consisting of peak at 114 and $156 \mathrm{~cm}^{-1}$ which corresponds to $\mathrm{Mg}_{3} \mathrm{Sb}_{2}$. Thus, the peaks of graphene and $\mathrm{Mg}_{3} \mathrm{Sb}_{2}$ for nanocomposites indicate that both phases coexist. The Raman spectra of bare $\mathrm{Mg}_{3} \mathrm{Sb}_{2}$ (as shown in inset; Fig. 2) consists of only two peaks at 118 and 147 $\mathrm{cm}^{-1}$. However, in case of nanocomposite $\mathrm{Mg}_{3} \mathrm{Sb}_{2} / \mathrm{GNS}(80: 1)$, there is a little shift to the lower side as compared the Raman shifts of $\mathrm{Mg}_{3} \mathrm{Sb}_{2}$. This is due to the coexistence of $\mathrm{Mg}_{3} \mathrm{Sb}_{2}$ and GNS in the nanocomposite. It can be noted that the Raman spectra only provide the statistical average of the powder sample, where a huge number of graphene sheets in single-, double-or few layered forms coexist. Thus, graphene can be distinguished as three different layers such as single, double, and few layers in more generalized way as suggested by Geim et $a .^{82}$ and hence practically the graphene in $\mathrm{Mg}_{3} \mathrm{Sb}_{2} / \mathrm{GNS}$

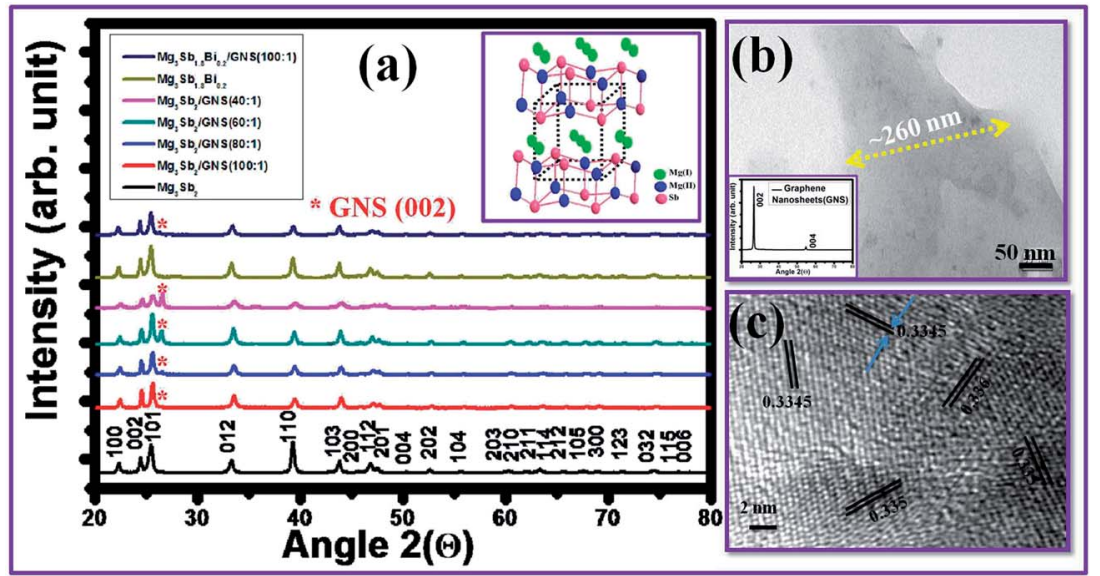

Fig. 1 (a) X-ray diffraction (XRD) pattern of $\mathrm{Mg}_{3} \mathrm{Sb}_{2} / \mathrm{GNS}$ nanocomposites with mass ratio of $100: 1,80: 1,60: 1,40: 1$ and for $\mathrm{Mg}_{3} \mathrm{Sb}_{1.8} \mathrm{Bi}_{0.2} /$ GNS with $80: 1$. Inset of (a) shows the schematic diagram of layered crystal structure of $\mathrm{Mg}_{3} \mathrm{Sb}_{2}$ showing the anionic framework of $\left[\mathrm{Mg}_{2} \mathrm{Sb}_{2}\right]^{2-}$ with double layer and $\mathrm{Mg}^{2+}$ cations between the layers. (b) The TEM image of reduced GNS. Inset (b) shows the XRD of the reduced GNS. (c) HRTEM image of GNS indicating excellent crystallinity. 
nanocomposite can be regarded as "graphene" in the form of few layered.

The coefficient of thermal expansion (CTE) can give the idea of dimensional changes occurred in nanocomposites with increasing temperature at defined load. It also gives the idea of bonding between the reinforcing constituent in the nanocomposites. The linear CTEs of the GNS, $\mathrm{Mg}_{3} \mathrm{Sb}_{2}$ and $\mathrm{Mg}_{3} \mathrm{Sb}_{2} /$ GNS nanocomposites pellets were measured in the temperature range $50-500{ }^{\circ} \mathrm{C}$. A high value of CTE of $310.5 \times 10^{-6} /{ }^{\circ} \mathrm{C}$ in case of GNS pellet was observed, which is due to poor bonding between the few layer graphene suggesting a linear shrinkage in the pellet with increasing temperature and as a consequence thermal stresses exert on the few layer graphene. On the other hand, in case of matrix $\mathrm{Mg}_{3} \mathrm{Sb}_{2}$ a reasonably small value of CTE $\sim 18.96 \times 10^{-6} /{ }^{\circ} \mathrm{C}$ was revealed resulting a strong bonding between constituent which arrest the shrinkage with increasing temperature. Interestingly, in case of $\mathrm{Mg}_{3} \mathrm{Sb}_{2} / \mathrm{GNS}$ nanocomposites, the CTE $\sim 23.46 \times 10^{-6} /{ }^{\circ} \mathrm{C}$ was observed, which is slightly larger than the CTE of the bare $\mathrm{Mg}_{3} \mathrm{Sb}_{2}$ matrix indicating a weak bonding between GNS and $\mathrm{Mg}_{3} \mathrm{Sb}_{2}$.

We have earlier reported the detailed electronic structure study of bare $\mathrm{Mg}_{3} \mathrm{Sb}_{2}$ using XPS core level and valence band spectra. ${ }^{8}$ Here, we have employed the XPS to compare the electronic structure of bare $\mathrm{Mg}_{3} \mathrm{Sb}$ and $\mathrm{Mg}_{3} \mathrm{Sb}_{2} /$ GNS nanocomposites. Fig. 3 shows XPS survey spectra of bare $\mathrm{Mg}_{3} \mathrm{Sb}_{2}$, GNS and $\mathrm{Mg}_{3} \mathrm{Sb}_{2} / \mathrm{GNS}$ nanocomposites over wide binding energy (BE) range. Spectrum of GNS (bottom) shows the presence of only carbon related features and absence of $\mathrm{O} 1$ s and any other feature verifies the purity of GNS. It can be noted that finite amount of $\mathrm{O}$ 1s signal in XPS survey spectrum of GNS has been reported in several recent reports of GNS synthesis using different routes. ${ }^{83-85}$ Usually GNS samples are obtained by the reduction of graphite oxide (GO) and it is not always possible to reduce the attached oxygen functional group completely which is detrimental to the electrical properties of graphene. However, in our case, almost complete absence of $\mathrm{O}$ 1s signal indicates the effectiveness of used synthesis procedure in removing oxygen functional group.

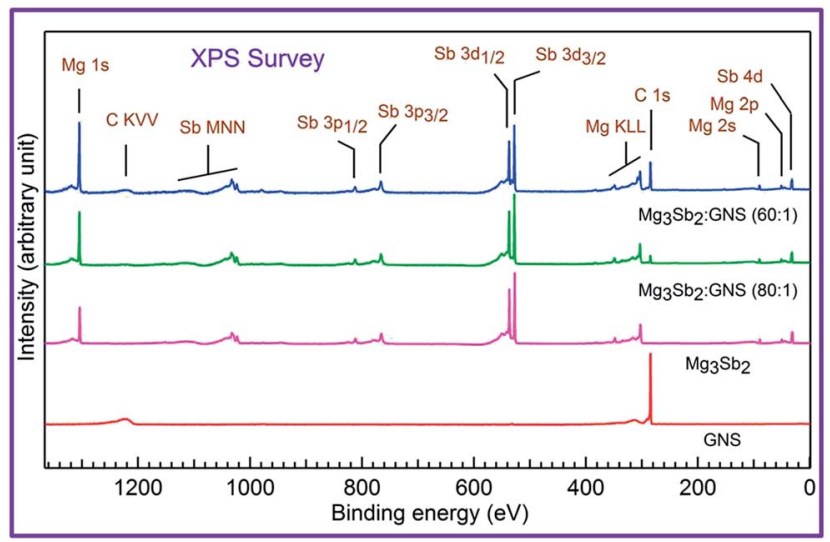

Fig. 3 XPS survey spectrum of pure GNS, bare $\mathrm{Mg}_{3} \mathrm{Sb}_{2}$ and $\mathrm{Mg}_{3} \mathrm{Sb}_{2} /$ GNS nanocomposites over wide binding energy range. All the features in the spectra have been identified. All the spectra have been staggered vertically for clarity of presentation.
Survey spectrum of bare $\mathrm{Mg}_{3} \mathrm{Sb}_{2}$ also confirms the purity of the material as we only see the $\mathrm{Mg}$ and $\mathrm{Sb}$ related features. ${ }^{8} \mathrm{We}$ clearly observe the emergence of $\mathrm{C} 1 \mathrm{~s}$ signal in the $\mathrm{Mg}_{3} \mathrm{Sb}_{2} / \mathrm{GNS}$ nanocomposites. The $\mathrm{C}$ 1s signal increases with increasing mass ratio of GNS which is the evidence of increasing inclusion of GNS in the nanocomposite samples for larger mass ratio of GNS. We have observed the inclusion of GNS in all nanocomposite samples reported here by the presence of $\mathrm{C} 1 \mathrm{~s}$ signal (spectra not shown here). We have mainly focused our XPS analysis on $\mathrm{Mg}_{3} \mathrm{Sb}_{2} / \mathrm{GNS}$ (80:1) sample as it performs best among other nanocomposites reported here.

We have acquired the high resolution C 1s XPS core level spectra to confirm the quality of GNS and to identify the presence of any other functional group attached with it. C 1s core level for GNS has been fitted using six Gaussian-Lorentzian components using a least $\chi^{2}$ iterative program after Shirley background subtraction (Fig. 4, bottom spectra).

The individual deconvoluted components (shaded region) correspond to different functional groups attached with $\mathrm{C}$ as identified in the Fig. 4 (graphitic $\mathrm{sp}^{2} \mathrm{C}=\mathrm{C}$ at $284.55 \mathrm{eV}, \mathrm{sp}^{3} \mathrm{C}-\mathrm{C}$ at $284.95 \mathrm{eV}, \mathrm{C}-\mathrm{O}$ at $286.2 \mathrm{eV}, \mathrm{C}=\mathrm{O}$ at $287.3 \mathrm{eV}, \mathrm{O}-\mathrm{C}=\mathrm{O}$ at 288.6 $\mathrm{eV}$ and $\pi-\pi^{*}$ shakeup feature at $290.5 \mathrm{eV} \mathrm{BE}$ ). Relative percentages of $\mathrm{C}=\mathrm{C}, \mathrm{C}-\mathrm{C}, \mathrm{C}-\mathrm{O}, \mathrm{C}=\mathrm{O}, \mathrm{O}-\mathrm{C}=\mathrm{O}$ are found to be $56,29,10,4$ and 1 respectively. Experimental uncertainty in $\mathrm{BE}$ position is $0.05 \mathrm{eV}$ and $\pm 5 \%$ of base value for determining the percentage. Full width at half maximum (FWHM) of $\mathrm{C}=\mathrm{C}$ component turns out to be $0.6 \mathrm{eV}$ and it varies between 1-1.15 $\mathrm{eV}$ for other C-functional group components. Energy position and FWHM of $\mathrm{sp}^{2} \mathrm{C}=\mathrm{C}$ and other components is in good agreement with earlier reports based on the analysis of $\mathrm{C} 1 \mathrm{~s}$ of a few layer graphene (FLG) and GNS..$^{\mathbf{8 3}, \mathbf{8 4}, \mathbf{8 6}-\mathbf{8 8}}$ Presence of dominating $\mathrm{sp}^{2} \mathrm{C}=\mathrm{C}$ establishes the graphene nature of our GNS. Similar fitting routine as of GNS has been applied to $\mathrm{C} 1$ s core

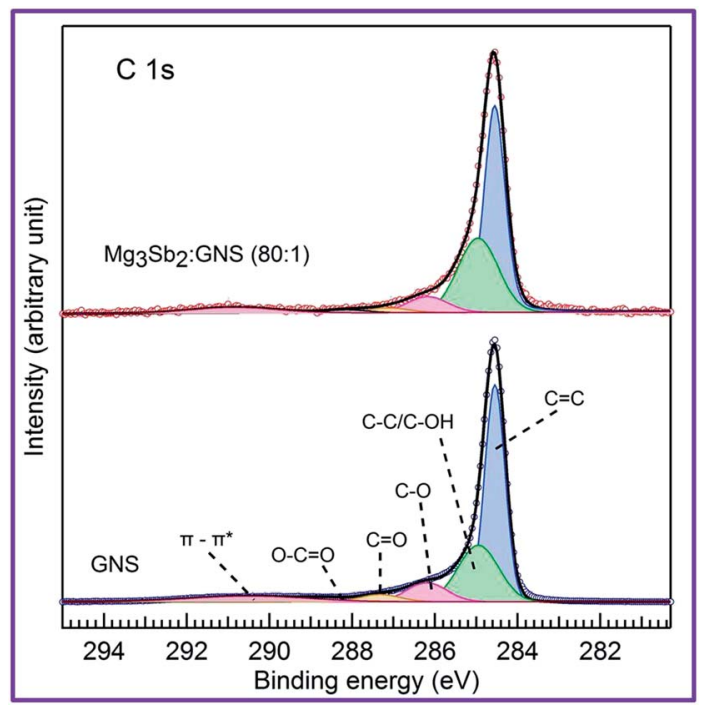

Fig. $4 \mathrm{C}$ 1s core level spectra for GNS (bottom) and $\mathrm{Mg}_{3} \mathrm{Sb}_{2} / \mathrm{GNS}$ (80 : 1) (top). Experimental data (open circles), fitted spectra (thick solid line) and deconvoluted fitting components (shaded region) are also shown. 


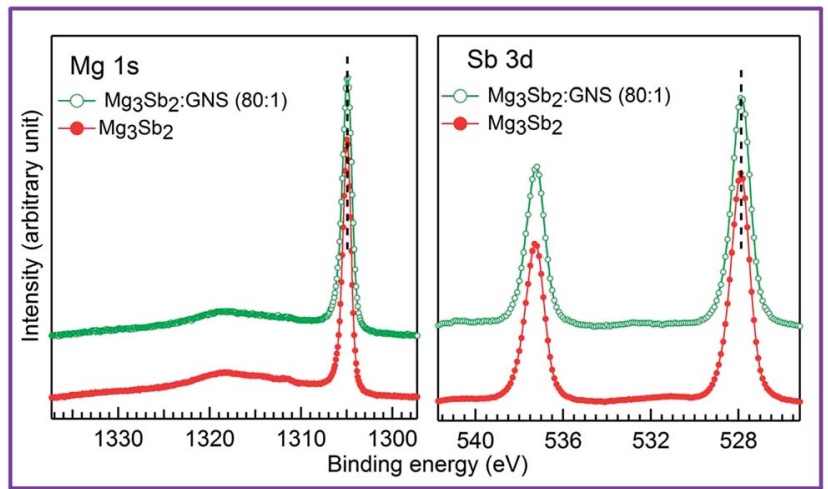

Fig. $5 \mathrm{Mg}$ 1s (left panel) and Sb 3d (right panel) core level spectra for bare $\mathrm{Mg}_{3} \mathrm{Sb}_{2}$ and nanocomposite $\mathrm{Mg}_{3} \mathrm{Sb}_{2} / \mathrm{GNS}$ (80:1). All the spectra have been normalized to peak height for comparison and were staggered vertically for clarity of presentation. Dashed line tracks the binding energy position.

level spectrum of $\mathrm{Mg}_{3} \mathrm{Sb}_{2} / \mathrm{GNS}(80: 1)$. It is clearly evident from nanocomposite material related $\mathrm{C} 1 \mathrm{~s}$ fitting that graphene nature of GNS is preserved in nanocomposite $\mathrm{Mg}_{3} \mathrm{Sb}_{2} / \mathrm{GNS}$ (80:1). We observe slight increase in $\mathrm{C}-\mathrm{C} / \mathrm{C}-\mathrm{OH}$ component in $\mathrm{Mg}_{3} \mathrm{Sb}_{2} / \mathrm{GNS}(80: 1)$ compared to GNS and it could be attributed to the synthesis procedure of nanocomposites (wet chemical synthesis followed by further milling and SPS).

The $\mathrm{Mg}$ 1s and $\mathrm{Sb} 3 \mathrm{~d}$ core level spectra for bare $\mathrm{Mg}_{3} \mathrm{Sb}_{2}$ and nanocomposite $\mathrm{Mg}_{3} \mathrm{Sb}_{2} / \mathrm{GNS}(80: 1)$ are shown in Fig. 5 . We do not observe any appreciable change in the BE position and line shape of core levels between bare and nanocomposite samples. It suggests that bonding between GNS and $\mathrm{Mg}$ and $\mathrm{Sb}$ is either nonexistent or very weak. This observation is also in good agreement with our thermal expansion measurements which suggest loose bonding between GNS and $\mathrm{Mg}_{3} \mathrm{Sb}_{2}$.

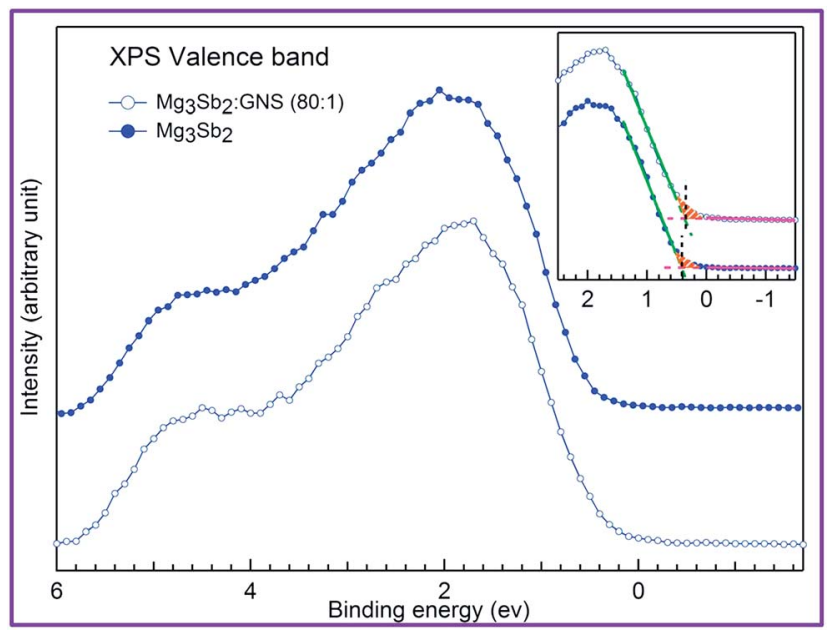

Fig. 6 XPS valence band spectra for bare $\mathrm{Mg}_{3} \mathrm{Sb}_{2}$ and nanocomposite $\mathrm{Mg}_{3} \mathrm{Sb}_{2} / \mathrm{GNS}(80: 1)$. Inset shows the near Fermi level $\left(E_{\mathrm{F}}\right)$ region. Straight lines (thick solid lines) show fitting of leading edge and background. Vertical dashed lines show the position of valence band maxima (VBM). Shaded area (patterned) represents density of states between $V B M$ and $E_{\mathrm{F}}$.
We have compared the XPS valence band (VB) spectra of bare $\mathrm{Mg}_{3} \mathrm{Sb}_{2}$ and nanocomposite $\mathrm{Mg}_{3} \mathrm{Sb}_{2} / \mathrm{GNS}(80: 1)$ as presented in Fig. 6. The VB is composed of mainly two features; main peak around $2 \mathrm{eV} \mathrm{BE}$ and another peak at around $4.6 \mathrm{eV} \mathrm{BE}$. These peaks are made up of $\mathrm{Sb} 5 \mathrm{p}$ states hybridized with $\mathrm{Mg}$ 3s states with dominant character of $\mathrm{Sb} 5 \mathrm{p} .{ }^{8}$ No significant change in energy positions or relative intensities of main features is observed between bare and composite material which also confirms the weak chemical interaction between $\mathrm{Mg}_{3} \mathrm{Sb}_{2}$ and GNS as observed in core level spectra (Fig. 5). Near Fermi level $\left(E_{\mathrm{F}}\right)$ energy region is shown in inset of Fig. 6 . We have determined the position of valence band maxima (VBM) from the cross-section of two straight line fits. ${ }^{8}$ We observe the small change in the BE position of VBM between bare $\mathrm{Mg}_{3} \mathrm{Sb}_{2}(0.4 \mathrm{eV})$ and nanocomposite $\mathrm{Mg}_{3} \mathrm{Sb}_{2} / \mathrm{GNS}(0.34 \mathrm{eV})$ with mass ratio $80: 1$ due to increase in p-type carriers in composite compared to bare $\mathrm{Mg}_{3} \mathrm{Sb}_{2}$. We also observe the small increase in the spectral weight near VBM (shown as patterned part) for composite material compared to bare $\mathrm{Mg}_{3} \mathrm{Sb}_{2}$ and it may be related to the increased electrical conductivity in $\mathrm{Mg}_{3} \mathrm{Sb}_{2} / \mathrm{GNS}$ nanocomposite.

In order to confirm the phase purity at macroscopic scale, homogeneity and compositional analysis of SPSed pellets of bare $\mathrm{Mg}_{3} \mathrm{Sb}_{2}$ and $\mathrm{Mg}_{3} \mathrm{Sb}_{2} / \mathrm{GNS}$ nanocomposite samples were performed by FE-SEM and HRTEM. The homogeneity of SPSed samples in bare $\mathrm{Mg}_{3} \mathrm{Sb}_{2}$ and $\mathrm{Mg}_{3} \mathrm{Sb}_{2} / \mathrm{GNS}$ nanocomposite for mass ratios $100: 1 ; 80: 1,60: 1$ and $40: 1$ were assessed by averaging the compositions obtained by energy dispersive X-ray analysis (EDAX) at 5 different regions of each sample. The average value of composition is shown in Table 1 marked as SEM-EDAX compositions. All the samples were found to be macroscopically homogeneous as revealed by SEM-EDAX analysis given in Table 1. Fig. 7 shows FE-SEM morphologies of bare $\mathrm{Mg}_{3} \mathrm{Sb}_{2}$ and $\mathrm{Mg}_{3} \mathrm{Sb}_{2} / \mathrm{GNS}$ nanocomposite with mass ratio $80: 1$.

The SEM image of SPSed bare $\mathrm{Mg}_{3} \mathrm{Sb}_{2}$ (Fig. 7 (a)) sample clearly reveals the homogeneous polycrystalline grains. Energy dispersive X-ray spectrum shown in Fig. 7(b) qualitatively reveals the presence of $\mathrm{Mg}$ and $\mathrm{Sb}$ without any minor impurities. The quantification data obtained from EDAX, indicates the composition of $\mathrm{Mg}_{3} \mathrm{Sb}_{2}$ phase. Fig. $7(\mathrm{c}-\mathrm{f})$ display FE-SEM morphologies of SPSed $\mathrm{Mg}_{3} \mathrm{Sb}_{2} / \mathrm{GNS}$ nanocomposite samples with mass ratio $80: 1$. The $\mathrm{Mg}_{3} \mathrm{Sb}_{2}$ particles appear to be uniformly confined on the surface of GNS as shown in Fig. 7(c). It is interesting to note that the $\mathrm{Mg}_{3} \mathrm{Sb}_{2}$ particles in the nanocomposite sample (the particle size ranging from $2.0 \mathrm{~nm}$ to 50 $\mathrm{nm}$ ) are significantly smaller than the particles in bare $\mathrm{Mg}_{3} \mathrm{Sb}_{2}$ (the particle size ranging from $100 \mathrm{~nm}$ to $500 \mathrm{~nm}$ ). In order to see the consistent behavior of graphene introduction on reducing the size of $\mathrm{Mg}_{3} \mathrm{Sb}_{2}$ particle, SEM measurements were conducted on all the nanocomposites with mass ratio $100: 1$, $60: 1$ and $40: 1$ which are shown in ESI. $\dagger$ All of the nanocomposite samples show smaller particle size of $\mathrm{Mg}_{3} \mathrm{Sb}_{2}$ and decreases with increasing GNS concentration. Thus, we believe that graphene refined the size of $\mathrm{Mg}_{3} \mathrm{Sb}_{2}$ particles and generates reduced grain boundaries upon the formation of nanocomposites similar to the other reports for many other systems. ${ }^{64-68}$ Obviously, the graphene in $\mathrm{Mg}_{3} \mathrm{Sb}_{2}$ matrix prevents 
Table 1 Showing composition and various physical parameters

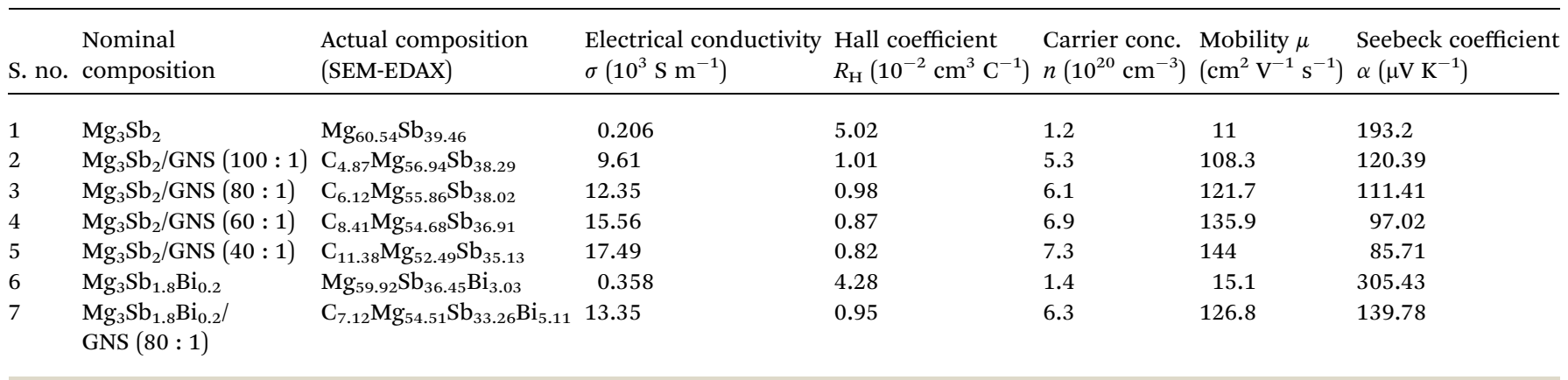
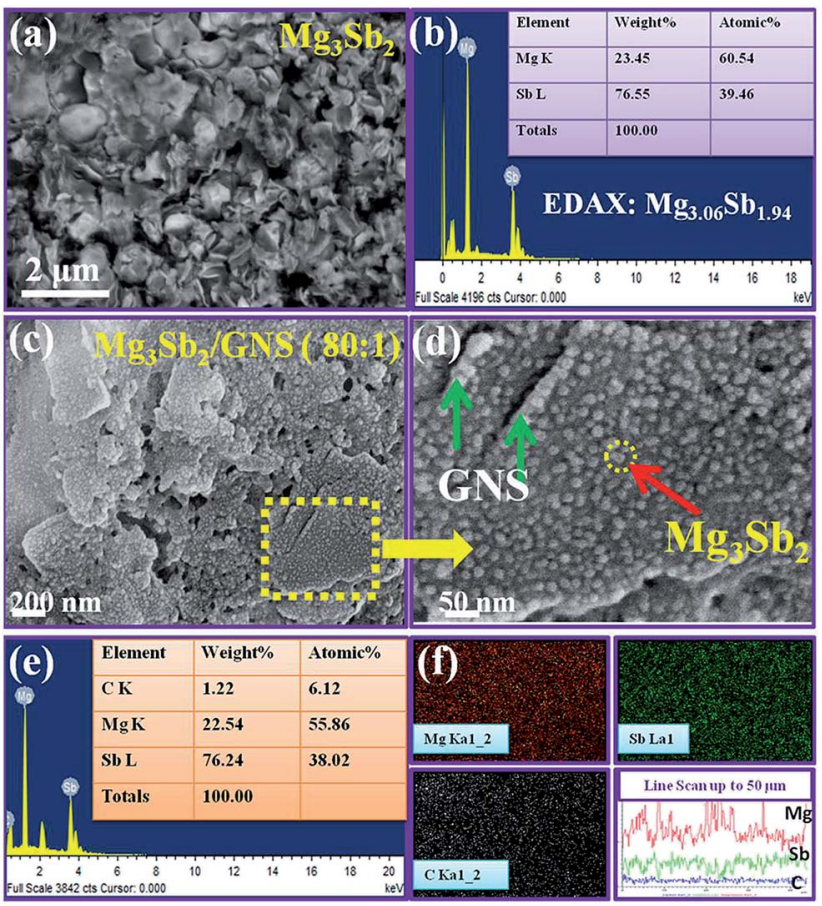

Fig. 7 (a) The SEM image of $\mathrm{Mg}_{3} \mathrm{Sb}_{2}$ showing homogeneous polycrystalline grains. (b) Energy dispersive $X$-ray spectrum (EDAX) of $\mathrm{Mg}_{3} \mathrm{Sb}_{2}$ indicating (inset (b)) the presence of $\mathrm{Mg}$ and $\mathrm{Sb}$ and quantification results to the composition of $\mathrm{Mg}_{3} \mathrm{Sb}_{2}$ phase. (c and d) Magnified FE-SEM image of $\mathrm{Mg}_{3} \mathrm{Sb}_{2} / \mathrm{GNS}$ nanocomposite with mass ratio $80: 1$ showing uniformly anchored $\mathrm{Mg}_{3} \mathrm{Sb}_{2}$ particles on the graphene nanosheets. (e) The SEM-EDAX analysis of $\mathrm{Mg}_{3} \mathrm{Sb}_{2} / \mathrm{GNS}$ nanocomposite with mass ratio 80 : 1showing presence of $\mathrm{Mg}_{3} \mathrm{Sb}_{2}$ with graphene. (f) FE-SEM elemental mapping of $\mathrm{Mg}$, $\mathrm{Sb}$ and $\mathrm{C}$ along with the line scan of the sample upto $50 \mu \mathrm{m}$.

the growth of grain boundary. The SEM-EDAX analysis (Fig. 7(e)) clearly reveals the presence of $\mathrm{Mg}_{3} \mathrm{Sb}_{2}$ with graphene. The EDAX-mapping and line scan upto large region of sample were also probed on this nanocomposite samples to find the presence of any minor impurities other than $\mathrm{Mg}, \mathrm{Sb}$ and $\mathrm{C}$. Evidently, no impurities other than constituents of the nanocomposite were observed, showing the purity of the nanocomposite material.

The TEM investigation of SPSed $\mathrm{Mg}_{3} \mathrm{Sb}_{2}$ sample was carried out to check the purity of sample before it can be deployed to fabricate the nanocomposite materials. Fig. 8(a) presents bright field image of $\mathrm{Mg}_{3} \mathrm{Sb}_{2}$ showing a polycrystalline sample with sizes ranging from $100 \mathrm{~nm}$ to $500 \mathrm{~nm}$. A corresponding selected area electron diffraction pattern (SAEDP) shows a set of Debye rings with fine sharp spots overlapping on individual rings (Fig. 8(b)) confirming the material to be $\beta-\mathrm{Mg}_{3} \mathrm{Sb}_{2}$ hexagonal crystal structure (space group $P \overline{3} m 1$.). Several lattice scale images (Fig. 8(c)) were recorded revealing different orientation of $\mathrm{Mg}_{3} \mathrm{Sb}_{2}$ and excellent crystallinity of the samples was realized. EDAX analysis [Fig. 8(d)] clearly reveals the elemental Mg and $\mathrm{Sb}$ peaks with composition very close to the nominal $\mathrm{Mg}_{3} \mathrm{Sb}_{2}$.

Fig. 9(a) represents a typical bright field electron micrograph of SPSed $\mathrm{Mg}_{3} \mathrm{Sb}_{2} / \mathrm{GNS}$ nanocomposite sample with mass ratio 80 : 1 showing the $\mathrm{Mg}_{3} \mathrm{Sb}_{2}$ particles with sizes ranging from 2.0 $\mathrm{nm}$ to $50 \mathrm{~nm}$ which is much smaller than the sizes of bare
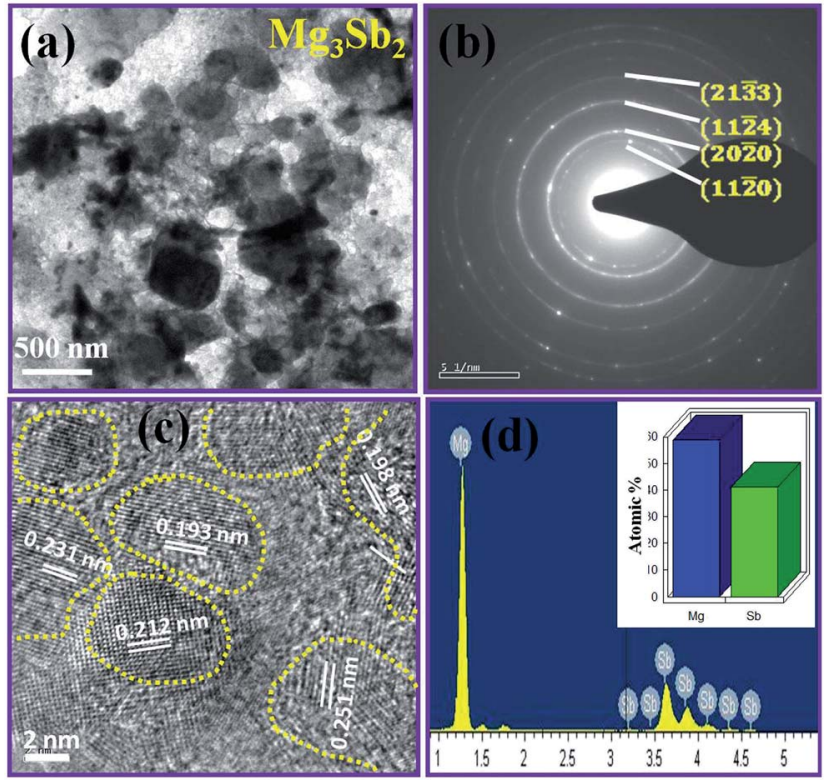

Fig. 8 (a) TEM image obtained from the specimen of $\mathrm{Mg}_{3} \mathrm{Sb}_{2}$ showing highly densified grains (b) SAED pattern corresponding to $\mathrm{Mg}_{3} \mathrm{Sb}_{2}$, revealing $\beta-\mathrm{Mg}_{3} \mathrm{Sb}_{2}$-type hexagonal structure, (c) the HRTEM image of $\mathrm{Mg}_{3} \mathrm{Sb}_{2}$ exhibiting the presence of different orientations of the crystallographic planes and their interface boundaries. (d) EDAX spectrum recorded from $\mathrm{Mg}_{3} \mathrm{Sb}_{2}$, confirms the composition of $\mathrm{Mg}_{3} \mathrm{Sb}_{2}$. 
$\mathrm{Mg}_{3} \mathrm{Sb}_{2}$. Obviously, the $\mathrm{Mg}_{3} \mathrm{Sb}_{2}$ particles are found to be anchored on the surface of graphene nano sheets. The decrease in the sizes of $\mathrm{Mg}_{3} \mathrm{Sb}_{2}$ particles in $\mathrm{Mg}_{3} \mathrm{Sb}_{2} / \mathrm{GNS}$ nanocomposites indicates that the GNS in $\mathrm{Mg}_{3} \mathrm{Sb}_{2}$ matrix suppresses the growth of the grain boundaries which is consistent with our SEM investigation. ${ }^{64-68}$ The presence of GNS can easily be discerned in Fig. 9(b \& c) as the lattice fringes corresponding to GNS can be clearly identified. The HRTEM shown in the inset of Fig. 9(c) clearly shows both phases with orientational relationship (002) GNS//(101) $\mathrm{Mg}_{3} \mathrm{Sb}_{2}$. Fig. 9(d) displays HRTEM image showing only $\mathrm{Mg}_{3} \mathrm{Sb}_{2}$ grains, no GNS was resolved at such high magnification. This could be due to either the microscopic condition are not optimal or depth of focus for the two phases were different to be detected simultaneously. Fig. 9(e) shows the schematic reaction mechanism for the formation of $\mathrm{Mg}_{3} \mathrm{Sb}_{2} /$ GNS nanocomposite.

In order to understand the impact of such novel fabricated nanocomposite with graphene as nanocomposite additive on the thermoelectric performance of bare undoped and Bi doped
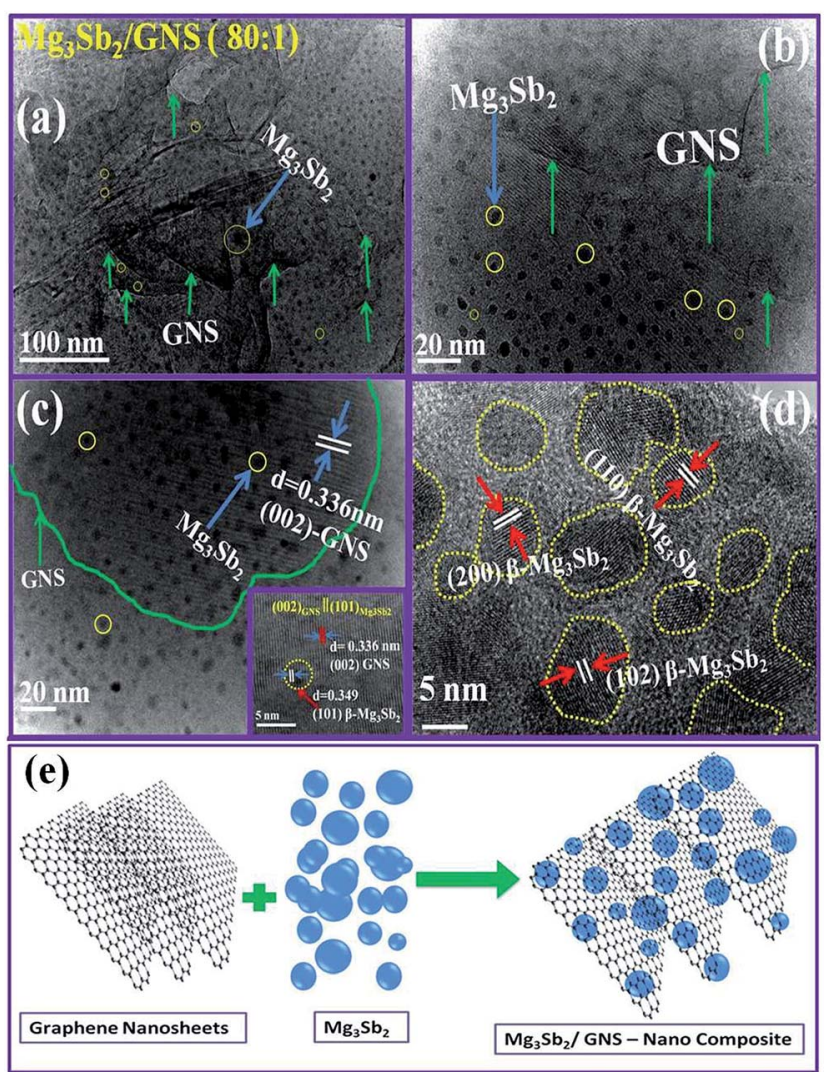

Fig. 9 (a) TEM image of $\mathrm{Mg}_{3} \mathrm{Sb}_{2} / \mathrm{GNS}(80: 1)$ nanocomposite showing uniformly anchoring of $\mathrm{Mg}_{3} \mathrm{Sb}_{2}$ particles on the surface of graphene nanosheets. ( $b$ and c) Magnified TEM images of $\mathrm{Mg}_{3} \mathrm{Sb}_{2} / \mathrm{GNS}(80: 1)$ nanocomposite showing more clearly the anchored $\mathrm{Mg}_{3} \mathrm{Sb}_{2}$ particles on to the sheet of graphene nanosheets and the inset (c) shows an orientational relationship (002)GNS//(101) $\mathrm{Mg}_{3} \mathrm{Sb}_{2}$ between the two phases. (d) HRTEM images of $\mathrm{Mg}_{3} \mathrm{Sb}_{2} / \mathrm{GNS}$ (80:1) nanocomposite showing only $\mathrm{Mg}_{3} \mathrm{Sb}_{2}$ grains, no GNS was resolved at such high magnification. (e) Schematic diagram of reaction mechanism occurred during the fabrication of $\mathrm{Mg}_{3} \mathrm{Sb}_{2} / \mathrm{GNS}$ nanocomposite.
$\mathrm{Mg}_{3} \mathrm{Sb}_{2}$, all the nanocomposites have been subjected to thermal and electronic transport measurements. The electronic and thermal transport properties of all the nanocomposites have been compared with the parent $\mathrm{Mg}_{3} \mathrm{Sb}_{2}$ material. Fig. 10 displays the temperature dependence of electrical conductivity $\sigma$, of $\mathrm{Mg}_{3} \mathrm{Sb}_{2} / \mathrm{GNS}$ nanocomposite for different mass ratios.

The electrical conductivity of all the nanocomposites increased with rising temperature displaying semiconducting behavior. Moreover, regardless of the temperature, electrical conductivity increases monotonously with increasing GNS concentration and reaches its maximum value for the nanocomposite with mass ratio $40: 1$. The various room temperature physical properties are shown in Table 1 . The $\mathrm{Mg}_{3} \mathrm{Sb}_{2} / \mathrm{GNS}$ nanocomposites exhibit an increased electrical conductivity compared to bare $\mathrm{Mg}_{3} \mathrm{Sb}_{2}$ over the entire temperature range. The electrical conductivity $\sigma$ can be expressed by a relation as

$$
\sigma=n e \mu
$$

where $n$ is the carrier concentration, $e$ is the charge of an electron and $\mu$ is the carrier mobility. Thus the enhancement in the electrical conductivity for $\mathrm{Mg}_{3} \mathrm{Sb}_{2} / \mathrm{GNS}$ nanocomposites may be attributed to either increase in carrier concentration, or an increase in carrier mobility. The Table 1 clearly demonstrates the increasing $n$ and $\mu$, simultaneously with increasing GNS concentration. The maximum carrier concentration and mobility was observed for the $\mathrm{Mg}_{3} \mathrm{Sb}_{2} / \mathrm{GNS}$ nanocomposite with mass ratio $40: 1$. For example, $n=7.3 \times 10^{20} \mathrm{~cm}^{-3}$ and $\mu=144$ $\mathrm{cm}^{2} \mathrm{~V}^{-1} \mathrm{~s}^{-1}$ for the nanocomposite with mass ratio $40: 1$, which is much higher than that of bare $\mathrm{Mg}_{3} \mathrm{Sb}_{2}\left(n=1.1 \times 10^{20} \mathrm{~cm}^{-3}\right.$ and $\mu=11 \mathrm{~cm}^{2} \mathrm{~V}^{-1} \mathrm{~s}^{-1}$ ). A systematic increase in the mobility was noticed in all the nanocomposites. Thus such a significant increase in the electrical conductivity is attributed primarily due to significant increase in $\mu$ and moderate increase in $n$. The rationale for this is that the pristine few layered graphene

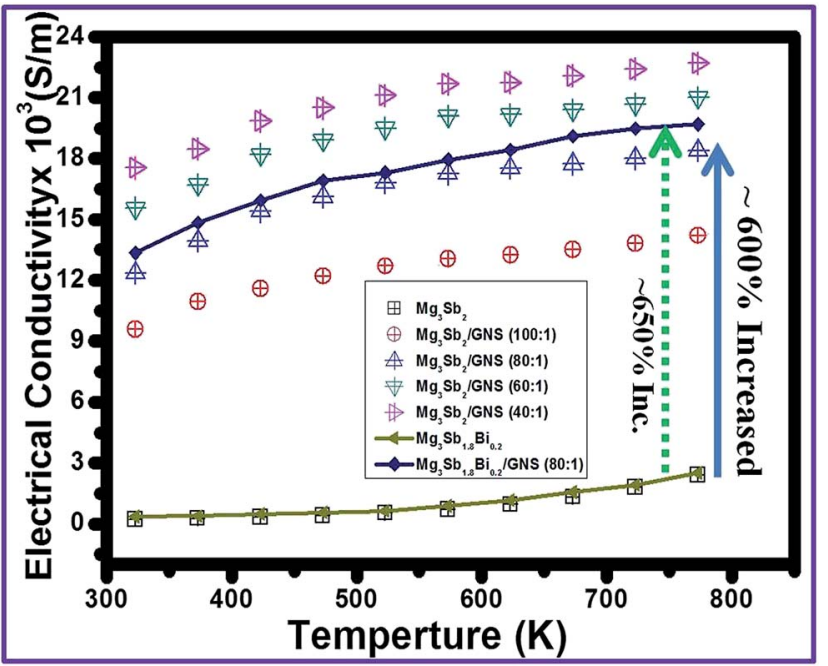

Fig. 10 Temperature dependence of Electrical conductivity of $\mathrm{Mg}_{3} \mathrm{Sb}_{2} / \mathrm{GNS}$ nanocomposite with mass ratio $100: 1,80: 1,60: 1$, $40: 1$ and for $\mathrm{Mg}_{3} \mathrm{Sb}_{1.8} \mathrm{Bi}_{0.2} / \mathrm{GNS}$ nanocomposites with mass ratio $80: 1$. 
reveals p-type thermoelectric properties and the graphene with its unique 2D planar structure has ultra high electron mobility (more than $20000 \mathrm{~cm}^{2} \mathrm{~V}^{-1} \mathrm{~s}^{-1}$ ). ${ }^{45}$ It has been suggested that the graphene in the nanocomposite may supply large number of extra transmission channels for electrons ${ }^{58}$ to take part in the transport which significantly improves the electrical conductivity. We speculate that same phenomenon would have taken place in the present nanocomposites. It is worth mentioning that the explanation why graphene enhances ultrahigh $\mu$ and significantly larger $\sigma$ is entirely plausible and exact physical mechanism still requires further investigation.

The temperature dependent Seebeck coefficients for bare $\mathrm{Mg}_{3} \mathrm{Sb}_{2}$ and $\mathrm{Mg}_{3} \mathrm{Sb}_{2} / \mathrm{GNS}$ nanocomposites are shown in Fig. 11(a). The Seebeck coefficient of all the nanocomposites is positive in the whole temperature range, indicating that majority of the carriers are holes which is consistent with the Hall measurement.

With the introduction of GNS, the Seebeck coefficients at room temperature decrease for all the nanocomposites and maintained such decrement throughout the whole temperature range as compared to that of bare $\mathrm{Mg}_{3} \mathrm{Sb}_{2}$. The decrease in Seebeck coefficient at room temperature is consistent with associated increase in carrier concentration. This phenomenon of inverse relation between $\alpha$ and $\sigma$ can be explained by the equation, ${ }^{65,89,90}$

$$
\alpha= \pm \frac{k_{\mathrm{B}}}{e}\left[2+\ln \frac{2\left(2 \pi m^{*} k_{\mathrm{B}} T\right)^{\frac{3}{2}}}{h^{3} n}\right]
$$

where $m^{*}$ is the effective mass relating the density of states and $n$, the carrier concentration. As noted above, the introduction of GNS induces large carrier concentration and hence according to the equation, the $\alpha$ is reduced. The absolute values of Seebeck coefficients of both bare $\mathrm{Mg}_{3} \mathrm{Sb}_{2}$ and $\mathrm{Mg}_{3} \mathrm{Sb}_{2}$ /GNS nanocomposite increase with temperature and attain a peak values at a certain temperature, and then further followed by a decreasing trend at higher temperature. This can be accounted to an increased number of thermally excited minority carriers at higher temperature leading to decreased Seebeck coefficient. Fig. 11(b) displays the power factor $\left(\mathrm{PF}=\alpha^{2} \sigma\right)$ of bare $\mathrm{Mg}_{3} \mathrm{Sb}_{2}$ and $\mathrm{Mg}_{3} \mathrm{Sb}_{2} / \mathrm{GNS}$ nanocomposites. The nanocomposites exhibit higher power factor compared to bare $\mathrm{Mg}_{3} \mathrm{Sb}_{2}$ which is mainly ascribed to the increased $\sigma$ due to introduction of GNS in the $\mathrm{Mg}_{3} \mathrm{Sb}_{2}$ matrix. The highest power factor was optimized for the $\mathrm{Mg}_{3} \mathrm{Sb}_{2} / \mathrm{GNS}$ nanocomposites with mass ratio of $80: 1$ at $673 \mathrm{~K}$. The maximum power factor for this nanocomposite was realized to be $4.5 \times 10^{-4} \mathrm{~W} \mathrm{~m}^{-1} \mathrm{~K}^{-2}$ at $673 \mathrm{~K}$ which is $130 \%$ larger than the bare $\mathrm{Mg}_{3} \mathrm{Sb}_{2}\left(\mathrm{PF}=1.98 \times 10^{-4} \mathrm{~W} \mathrm{~m}^{-1} \mathrm{~K}^{-2}\right)$. The optimized higher power factor of $\mathrm{Mg}_{3} \mathrm{Sb}_{2} / \mathrm{GNS}$ with mass ratio: $80: 1$ was resulted due to a large increase in the electrical conductivity ( $\sim 600 \%$ larger value than bare $\mathrm{Mg}_{3} \mathrm{Sb}_{2}$ ). Thus incorporation of graphene in $\mathrm{Mg}_{3} \mathrm{Sb}_{2}$ thermoelectric matrix is beneficial by increasing the electrical conductivity while inducing less effect on the Seebeck coefficient which in turn increases the large power factor $\left(\mathrm{PF}=\alpha^{2} \sigma\right)$.

In addition to $\alpha$ and $\sigma$, the thermal conductivity, $\kappa$ is also an important parameter for thermoelectric material. Fig. 12(a) displays the temperature dependence of thermal conductivity $\kappa$ (T) of bare $\mathrm{Mg}_{3} \mathrm{Sb}_{2}$ and $\mathrm{Mg}_{3} \mathrm{Sb}_{2} / \mathrm{GNS}$ nanocomposites. The incorporation of GNS into $\mathrm{Mg}_{3} \mathrm{Sb}_{2}$ leads to increased thermal conductivity and increases with increasing GNS content. For instance, the total thermal conductivity $\left(\kappa=2.4 \mathrm{~W} \mathrm{~m}^{-1} \mathrm{~K}^{-1}\right)$ of $\mathrm{Mg}_{3} \mathrm{Sb}_{2} / \mathrm{GNS}$ nanocomposite for higher GNS concentration, say for $40: 1$ is much larger than that of $\mathrm{Mg}_{3} \mathrm{Sb}_{2}\left(\kappa=1.39 \mathrm{~W} \mathrm{~m}^{-1}\right.$ $\mathrm{K}^{-1}$ ). This could be attributed to significant contribution from electronic part which could have been induced by GNS inclusions. The temperature dependent thermal conductivity of bare $\mathrm{Mg}_{3} \mathrm{Sb}_{2}$ and all the nanocomposites $\mathrm{Mg}_{3} \mathrm{Sb}_{2} / \mathrm{GNS}$ decrease with temperature, which indicates that the phonon conductivity dominates. Interestingly, the nanocomposite $\mathrm{Mg}_{3} \mathrm{Sb}_{2} / \mathrm{GNS}$ with mass ratio $80: 1$ displayed a low thermal conductivity at high temperature than the bare $\mathrm{Mg}_{3} \mathrm{Sb}_{2}$ which is reduced by $15 \%$ of the value of bare $\mathrm{Mg}_{3} \mathrm{Sb}_{2}$ at high temperature. The lattice thermal conductivity [Fig. 12(c)] including bipolar was obtained by subtracting the electronic thermal conductivity from the total measured thermal conductivity. The Wiedemann-Franz law has been used to calculate the electronic thermal conductivity $\left(\kappa_{\mathrm{e}}=L \sigma T\right.$, where $L$ is Lorenz number, $\sigma$, the electrical conductivity and $T$, the temperature in $\mathrm{K})$. Here, we use the

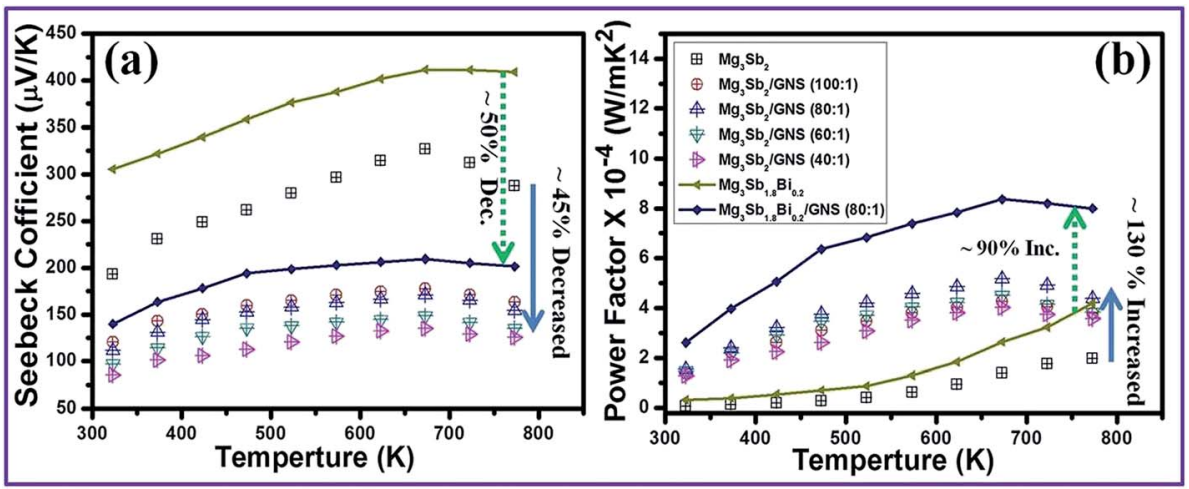

Fig. 11 Temperature dependence of (a) Seebeck coefficient and (b) power factor of $\mathrm{Mg}_{3} \mathrm{Sb}_{2} / \mathrm{GNS}$ nanocomposites with mass ratio of 100 : 1 , $80: 1,60: 1,40: 1$ and for $\mathrm{Mg}_{3} \mathrm{Sb}_{1.8} \mathrm{Bi}_{0.2} / \mathrm{GNS}$ nanocomposite with mass ratio $80: 1$. 


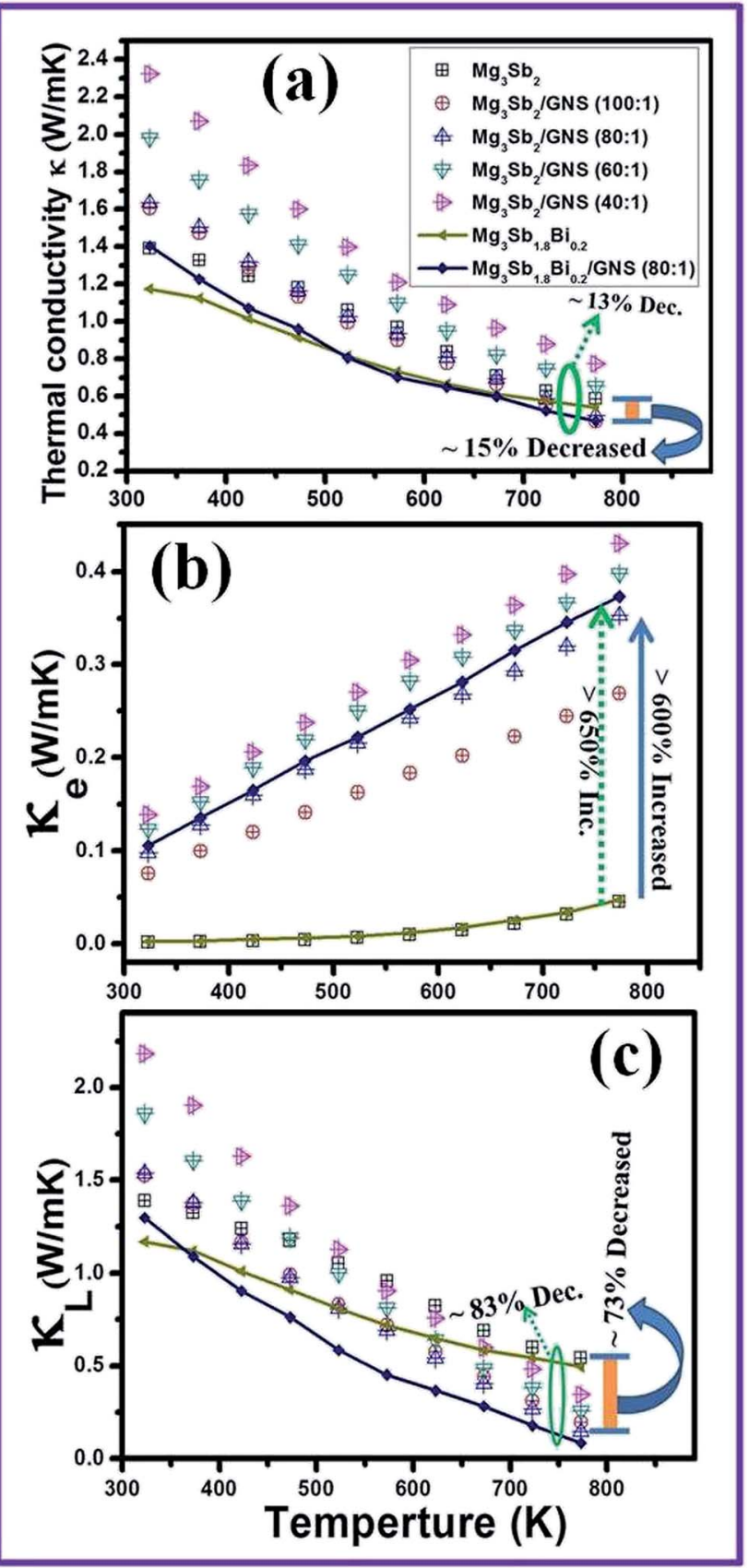

Fig. 12 Temperature dependence of (a) Thermal conductivity $(\kappa)$, (b) electronic thermal conductivity $\left(\kappa_{\mathrm{e}}\right)$ and (c) lattice thermal conductivity $\left(\kappa_{\mathrm{L}}\right)$ of $\mathrm{Mg}_{3} \mathrm{Sb}_{2} / \mathrm{GNS}$ nanocomposites with mass ratio of $100: 1,80: 1$, $60: 1,40: 1$ and for $\mathrm{Mg}_{3} \mathrm{Sb}_{1.8} \mathrm{Bi}_{0.2} / \mathrm{GNS}$ with $80: 1$.

temperature dependent Lorenz number ${ }^{\mathbf{9 1}}$ and the bipolar contribution was taken into account by assuming $\kappa_{\text {lattice }} \sim 1 / T{ }^{{ }^{92}}$ Fig. 12(c) represents the temperature dependent lattice thermal conductivity. The lattice thermal conductivity of all the samples was observed to decrease with increasing temperature (Fig. 12(c)), showing similar falling trend in the total thermal conductivity. The lattice thermal conductivity $\left(\kappa_{\mathrm{L}}=0.34 \mathrm{~W} \mathrm{~m} \mathrm{~m}^{-1} \mathrm{~K}^{-1}\right)$ of $\mathrm{Mg}_{3} \mathrm{Sb}_{2} / \mathrm{GNS}$ nanocomposite at $773 \mathrm{~K}$ is much smaller than the thermal conductivity $\left(\kappa_{\mathrm{L}}=0.54 \mathrm{~W} \mathrm{~m}^{-1} \mathrm{~K}^{-1}\right)$ of $\mathrm{Mg}_{3} \mathrm{Sb}_{2}$ at $773 \mathrm{~K}$.
However, a higher $\kappa_{\text {lattice }}$ for all the nanocomposites than their respective counterparts were noted at low temperature, which might be resulted due to large lattice thermal conductivity of graphene. The rationale behind this observation could be understood by considering the properties of graphene.

The graphene has large specific surface area apart from large $\kappa_{\text {lattice }}$ and hence, an inverse effect of graphene on the thermal conductivity may also be expected. However, we anticipate that large lattice thermal conductivity is observed due to later i.e. due to high lattice thermal conductivity of graphene. The large surface area of graphene providing more interfaces to scatter phonons may not be sufficient to dominate over the large lattice thermal conductivity due to graphene addition, which needs to be further investigated. The electronic thermal conductivities, $\kappa_{\mathrm{e}}$ for $\mathrm{Mg}_{3} \mathrm{Sb}_{2}$ and $\mathrm{Mg}_{3} \mathrm{Sb}_{2} / \mathrm{GNS}$ nanocomposites are displayed in Fig. 12(b). Obvious increases in the $\kappa_{\mathrm{e}}$ with GNS concentration for the nanocomposites were noted, owing to the increased electrical conductivities observed for the nanocomposites.

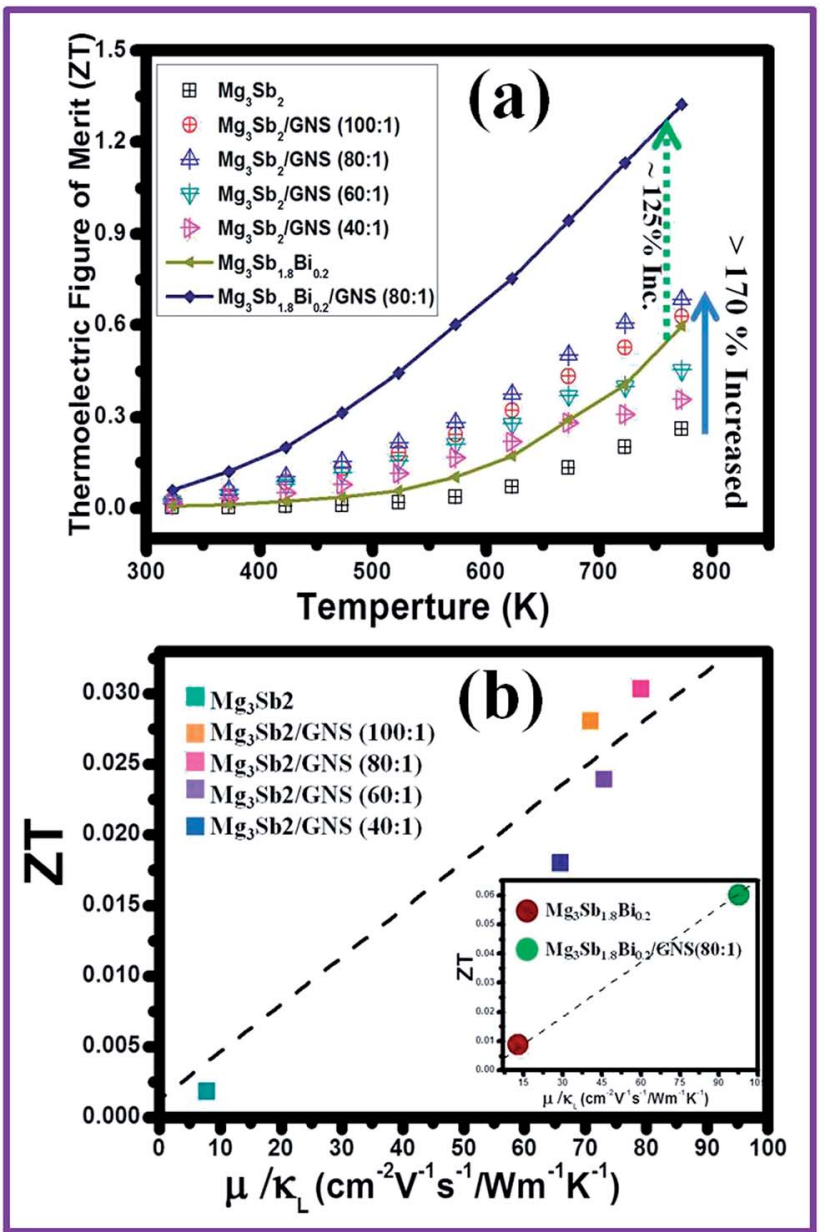

Fig. 13 (a) Temperature dependence of thermoelectric figure of merit (ZT) of $\mathrm{Mg}_{3} \mathrm{Sb}_{2} / \mathrm{GNS}$ nanocomposites with mass ratio of $100: 1,80: 1$, $60: 1,40: 1$ and for $\mathrm{Mg}_{3} \mathrm{Sb}_{1.8} \mathrm{Bi}_{0.2}$ /GNS nanocomposites with mass ratio of $80: 1$. (b) The graphs between $Z T$ vs. $\mu / \kappa_{\mathrm{L}}$ showing a linear increase with increasing the GNS concentration in the composite. Inset graph shows the similar trend for $\mathrm{Bi}$ doped $\mathrm{Mg}_{3} \mathrm{Sb}_{2}$ and its nanocomposite. 
The temperature dependence of $Z T$ of all the samples is calculated which is displayed in Fig. 13(a). The $Z T$ of the nanocomposites increases with rising temperature as presented in Fig. 13(a). The maximum $Z T \approx 0.71$ at temperature of $773 \mathrm{~K}$ for $\mathrm{Mg}_{3} \mathrm{Sb}_{2} / \mathrm{GNS}$ nanocomposite was optimized for the mass ratio $80: 1$, which is significantly enhanced than $Z T \approx 0.26$ at $773 \mathrm{~K}$ for bare $\mathrm{Mg}_{3} \mathrm{Sb}_{2} \cdot{ }^{8}$ Thus combining a large increase $(\sim 130 \%)$ in the power factor due to significant enhancement of electrical conductivity ( $600 \%)$, along with $15 \%$ reduction in the thermal conductivity at high temperature, the $Z T$ of the nanocomposite with mass ratio $80: 1$ was calculated to be about $170 \%$ larger than that of bare $\mathrm{Mg}_{3} \mathrm{Sb}_{2}$ sample.

Following similar strategy, GNS were also incorporated in a derivative of $\mathrm{Mg}_{3} \mathrm{Sb}_{2}$ with a nominal composition $\mathrm{Mg}_{3} \mathrm{Sb}_{1.8} \mathrm{Bi}_{0.2}$ to fabricate a nanocomposite of $\mathrm{Mg}_{3} \mathrm{Sb}_{1.8} \mathrm{Bi}_{0.2} / \mathrm{GNS}$ and thermoelectric properties were investigated. The optimized amount of GNS in the mass ratio of $80: 1$ was added. The temperature dependent behavior of all the thermoelectric parameters followed consistently the similar trends. Interestingly, graphene incorporation in this case too, leads to $650 \%$ improvement in the electrical conductivity, 90\% improvement in the power factor and $13 \%$ reduction in the thermal conductivity leading to a significant enhancement of $Z T$ about $125 \%$ in comparison to that of $\mathrm{Mg}_{3} \mathrm{Sb}_{1.8} \mathrm{Bi}_{0.2}$. Thus, graphene incorporation with its high mobility in the present Zintl phase compound provides an emerging strategy to enhance the thermoelectric performance of $\mathrm{Mg}_{3} \mathrm{Sb}_{2}$-based material. This strategy employed is summarized in Fig. 13(b) which clearly presents that large $\mu / \kappa_{\mathrm{L}}$ value results higher $Z T$ and this strategy of increasing mobility by incorporating GNS in $\mathrm{Mg}_{3} \mathrm{Sb}_{2}$-based Zintl compound was successfully demonstrated at room temperature. For this strategy to be effectively seen at higher temperature, high temperature Hall measurement is required which will be future avenue of the research. We believe that this strategy is not limited to only $\mathrm{Mg}_{3} \mathrm{Sb}_{2}$ based Zintl phase compound but may be efficiently deployed for improving thermoelectric performance of other Zintl phase compounds which are largely victim with the low electrical conductivity.

\section{Conclusion and future prospects}

Novel $\left(\mathrm{Mg}_{3} \mathrm{Sb}_{2}, \mathrm{Mg}_{3} \mathrm{Sb}_{1.8} \mathrm{Bi}_{0.2}\right) / \mathrm{GNS}$ nanocomposites have been fabricated by incorporating graphene nanosheets in presynthesized $\mathrm{Mg}_{3} \mathrm{Sb}_{2}$ and $\mathrm{Mg}_{3} \mathrm{Sb}_{1.8} \mathrm{Bi}_{0.2}$ precursors using wet mechanical milling and further rapid heating spark plasma sintering process. The addition of small fraction of GNS into $\mathrm{Mg}_{3} \mathrm{Sb}_{2}$ and $\mathrm{Mg}_{3} \mathrm{Sb}_{1.8} \mathrm{Bi}_{0.2}$ matrix resulted into the significant enhancement in the electrical conductivity $(\sim 600 \%$ and $\sim 650 \%$ respectively) and thereby increasing to a large power factor ( $\sim 130 \%$ and $\sim 90 \%$ respectively) of thermoelectric nanocomposites material. The thermal conductivity of the nanocomposites $\mathrm{Mg}_{3} \mathrm{Sb}_{2} / \mathrm{GNS}$ and $\mathrm{Mg}_{3} \mathrm{Sb}_{1.8} \mathrm{Bi}_{0.2} / \mathrm{GNS}$ at higher temperature are also decreased as compared to $\mathrm{Mg}_{3} \mathrm{Sb}_{2}$ and $\mathrm{Mg}_{3} \mathrm{Sb}_{1.8} \mathrm{Bi}_{0.2}$. Thus these nanocomposites outperform bare $\mathrm{Mg}_{3} \mathrm{Sb}_{2}$ and $\mathrm{Mg}_{3} \mathrm{Sb}_{1.8} \mathrm{Bi}_{0.2}$ and attain a $Z T \sim 0.71$ and a $Z T \sim 1.35$ at $773 \mathrm{~K}$ respectively which are much larger than $\mathrm{Mg}_{3} \mathrm{Sb}_{2}(Z T \sim$ 0.26) and $\mathrm{Mg}_{3} \mathrm{Sb}_{1.8} \mathrm{Bi}_{0.2}(Z T \sim 0.6)$ materials. Since these materials are made from abundant and non-toxic $\mathrm{Mg}, \mathrm{Sb}$ and graphene and thus make them a cheap alternative and finds widespread use over high scarcity and price of $\mathrm{Te}, \mathrm{Pb}$ used in commercialized state-of-the-art thermoelectric materials. A large boost in the electrical conductivity and reduced thermal conductivity at high temperature in $\mathrm{Mg}_{3} \mathrm{Sb}_{2} / \mathrm{GNS}$ nanocomposite with mass ratio $80: 1$ suggests that there is plenty of rooms for improvement of thermoelectric properties if a suitable concentration of GNS inclusion is optimized. It may be anticipated that an optimal amount of GNS can further refined the size of $\mathrm{Mg}_{3} \mathrm{Sb}_{2}$ particles and hence lattice thermal conductivity can be reduced for further boost in $Z T$ of such nanocomposites. Thus design of such nanocomposites combining Zintl phase with intrinsic properties of PGEC for the potential thermoelectric materials with GNS appears to be a very effective and promising path to be followed up for improving the thermoelectric properties. Off course, this strategy is not unique to $\mathrm{Mg}_{3} \mathrm{Sb}_{2}$-based Zintl phase and may be extended to other Zintl phase compounds possessing low electrical conductivity.

\section{Acknowledgements}

This work was supported by CSIR-TAPSUN (NWP- 54) programme entitled "Novel approaches for solar energy conversion under technologies and products for solar energy utilization through networking." The authors are grateful to the Director, Prof. R. C. Budhani (Director, CSIR-NPL), for his constant mentoring and support for this project. The authors thank Dr J. J. Pulikkotil (CSIR-NPL) and Dr Prabir Pal (CSIR-NPL) for useful discussions and comments. Dr A. M. Biradar (HOD, Materials Physics \& Engineering, CSIR-NPL) is gratefully acknowledged for his continuous encouragement to sucessesfully completing the work. We acknowledge Dr Sunil Pandey (NIMS University, Jaipur) for providing the room temperature Hall data. One of the authors $\mathrm{AB}$ greatly acknowledges UGC-CSIR for financial support. The technical support rendered by Mr Radhey Shyam, and Mr Naval Kishor Upadhyay is gratefully acknowledged.

\section{References}

1 G. Chen, M. S. Dresselhaus, G. Dresselhaus, J. P. Fleurial and T. Caillat, Int. Mater. Rev., 2003, 48, 45.

2 G. J. Snyder and E. S. Toberer, Nat. Mater., 2008, 7, 105.

3 J. Yang, H.-L. Yip and A. K.-Y. Jen, Adv. Energy Mater., 2013, 3, 549.

4 S. N. Girard, J. He, X. Zhou, D. Shoemaker, C. M. Jaworski, C. Uher, V. P. Dravid, J. P. Heremans and M. G. Kanatzidis, J. Am. Chem. Soc., 2011, 133, 16588.

5 H. Wang, Y. Pei, A. D. LaLonde and G. J. Snyder, Adv. Mater., 2011, 23, 1366.

6 L. Pan, D. Bérardan and N. Dragoe, J. Am. Chem. Soc., 2013, 135, 4914.

7 H. Wang, A. D. LaLonde, Y. Pei and G. J. Snyder, Adv. Funct. Mater., 2013, 23, 1586.

8 A. Bhardwaj, A. Rajput, A. K. Shukla, J. J. Pulikkotil, A. K. Srivastava, A. Dhar, G. Gupta, S. Auluck, D. K. Misra and R. C. Budhani, RSC Adv., 2013, 3, 8504. 
9 C. Heinrich, T. Day, W. G. Zeier, G. J. Snyder and W. Tremel, J. Am. Chem. Soc., 2014, 136, 442.

10 X. Liu, H. Wang, L. Hu, H. Xie, G. Jiang, G. J. Snyder, X. Zhao and T. Zhu, Adv. Energy Mater., 2013, 3, 1238.

11 J.-F. Li, W.-S. Liu, L.-D. Zhao and M. Zhou, NPG Asia Mater., 2010, 2, 152.

12 D. K. Misra, A. Bhardwaj and S. Singh, J. Mater. Chem., 2014, 2, 11913-11921.

13 G. Joshi, X. Yan, H. Wang, W. Liu, G. Chen and Z. Ren, Adv. Energy Mater., 2011, 1, 643.

14 K. Nielsch, J. Bachmann, J. Kimling and H. Böttner, Adv. Energy Mater., 2011, 1, 713.

15 S. Sumithra, N. J. Takas, D. K. Misra, W. M. Nolting, P. F. P. Poudeu and K. L. Stokes, Adv. Energy Mater., 2011, 1, 1141.

16 A. Bhardwaj, D. K. Misra, J. J. Pulikkotil, S. Auluck, A. Dhar and R. C. Budhani, Appl. Phys. Lett., 2012, 101, 133103.

17 J. P. Heremans, V. Jovovic, E. S. Toberer, A. Saramat, K. Kurosaki, A. Charoenphakdee, A. Yamanaka and G. J. Snyder, Science, 2008, 321, 554.

18 S. Y. Wang, X. J. Tan, G. J. Tan, X. Y. She, W. Liu, H. Li, H. J. Liu and X. F. Tang, J. Mater. Chem., 2012, 22, 13977.

19 Y. Z. Pei, X. Y. Shi, A. LaLonde, H. Wang, L. D. Chen and G. J. Snyder, Nature, 2011, 473, 66.

20 W. Liu, X. J. Tan, K. Yin, H. J. Liu, X. F. Tang, J. Shi, Q. J. Zhang and C. Uher, Phys. Rev. Lett., 2012, 108, 166601.

21 B. Paul, V. A. Kumar and P. Banerji, J. Appl. Phys., 2006, 108, 064322.

22 B. Poudel, Q. Hao, Y. Ma, Y. Lan, A. Minnich, B. Yu, X. Yan, D. Wang, A. Muto, D. Vashaee, X. Chen, J. Liu, M. S. Dresselhaus, G. Chen and Z. Ren, Science, 2008, 320, 634.

23 S. Yu, J. Yang, Y. Wu, Z. Han, J. Lu, Y. Xie and Y. Qian, J. Mater. Chem., 1998, 8, 1949.

24 J. Shen, T. Zhu, X. Zhao, S. Zhang, S. Yanga and Z. Yina, Energy Environ. Sci., 2010, 3, 1519.

25 M. E. Anderson, S. S. N. Bharadwaya and R. E. Schaak, J. Mater. Chem., 2010, 20, 8362.

26 S. Sumithra, N. J. Takas, D. K. Misra, W. M. Nolting, P. F. P. Poudeu and K. L. Stokes, Adv. Energy Mater., 2011, 1, 1141.

27 K. F. Hsu, S. Loo, F. Guo, W. Chen, J. S. Dyck, C. Uher, T. Hogan, E. K. Polychroniadis and M. G. Kanatzidis, Science, 2004, 303, 818.

28 J. Androulakis, K. F. Hsu, R. Pcionek, H. Kong, C. Uher, J. J. D'Angelo, A. Downey, T. Hogan and M. G. Kanatzidis, Adv. Mater., 2006, 18, 1170.

29 J. R. Sootsman, H. Kong, C. Uher, J. J. D'Angelo, C. I. Wu, T. P. Hogan, T. Caillat and M. G. Kanatzidis, Angew. Chem., 2008, 47, 8618.

30 K. Ahn, K. Biswas, J. He, I. Chung, V. Dravid and M. G. Kanatzidis, Energy Environ. Sci., 2013, 6, 1529.

31 R. Basu, S. Bhattacharya, R. Bhatt, M. Roy, S. Ahmad, A. Singh, M. Navaneethan, Y. Hayakawa, D. K. Aswal and S. K. Gupta, J. Mater. Chem. A, 2014, 2, 6922.
32 G. Joshi, H. Lee, Y. Lan, X. Wang, G. Zhu, D. Wang, R. W. Gould, D. C. Cuff, M. Y. Tang, M. S. Dresselhaus, G. Chen and Z. F. Ren, Nano Lett., 2008, 8, 4670.

33 E. S. Toberer, C. A. Cox, S. R. Brown, T. Ikeda, A. F. May, S. M. Kauzlarich and G. J. Snyder, Adv. Funct. Mater., 2008, 18, 2795.

34 A. Bhardwaj and D. K. Misra, RSC Adv., 2014, 4, 34552.

35 S. R. Brown, S. M. Kauzlarich, F. Gascoin and G. J. Snyder, Chem. Mater., 2006, 18, 1873.

36 G. J. Snyder, M. Christensen, E. Nishibori, T. Caillat and B. B. Iversen, Nat. Mater., 2004, 3, 458.

37 S. K. Bux, A. Zevalkink, O. Janka, D. Uhl, S. Kauzlarich, J. G. Snyder and J. P. Fleurial, J. Mater. Chem. A, 2014, 2, 215.

38 B. C. Sales, D. Mandrus and R. K. Williams, Science, 1996, 272, 1325.

39 J. W. Graff, X. Zeng, A. M. Dehkordi, J. He and T. M. Tritt, J. Mater. Chem. A, 2014, 2, 8933.

40 G. S. Nolas, J. L. Cohn, G. A. Slack and S. B. Schujman, Appl. Phys. Lett., 1998, 73, 178.

41 H. Kleinke, Chem. Mater., 2010, 22, 604.

42 F. Gascoin, S. Ottensmann, D. Stark, S. M. Haile and G. J. Snyder, Adv. Funct. Mater., 2005, 15, 1860.

43 X. J. Wang, M. B. Tang, J. T. Zhao, H. H. Chen and X. X. Yang, Appl. Phys. Lett., 2007, 90, 232107.

44 X. J. Wang, M. B. Tang, H. H. Chen, X. X. Yang, J. T. Zhao, U. Burkhardt and Y. Grin, Appl. Phys. Lett., 2009, 94, 092106. 45 S. J. Kim and M. G. Kanatzidis, Inorg. Chem., 2001, 40, 3781. 46 S. M. Park, E. S. Choi, W. Kang and S. J. Kim, J. Mater. Chem., 2002, 12, 1839.

47 S. J. Kim, J. R. Ireland, C. R. Kannewurf and M. G. Kanatzidis, J. Solid State Chem., 2000, 155, 55.

48 H. Zhang, J. T. Zhao, Y. Grin, X. J. Wang, M. B. Tang, Z. Y. Man, H. H. Chen and X. X. Yang, J. Chem. Phys., 2008, 129, 164713.

49 G. S. Pomrehn, A. Zevalkink, W. G. Zeier, A. van de Walle and G. J. Snyder, Angew. Chem., Int. Ed., 2014, 53, 3422.

50 K. S. Novoselov, D. Jiang, F. Schedin, T. J. Booth, V. V. Khotkevich, S. V. Morozov and A. K. Geim, Proc. Natl. Acad. Sci. U. S. A., 2005, 102, 10451.

51 Y. Zhang, Y.-W. Tan, H. L. Stormer and P. Kim, Nature, 2005, 438, 201.

52 D. A. Abanin, S. V. Morozov, L. A. Ponomarenko, R. V. Gorbachev, A. S. Mayorov, M. I. Katsnelson, K. Watanabe, T. Taniguchi, K. S. Novoselov, L. S. Levitov and A. K. Geim, Science, 2011, 332, 328.

53 J. H. Seol, I. Jo, A. L. Moore, L. Lindsay, Z. H. Aitken, M. T. Pettes, X. Li, Z. Yao, R. Huang, D. Broido, N. Mingo, R. S. Ruoff and L. Shi, Science, 2010, 328, 213.

54 A. K. Geim and K. S. Novoselov, Nat. Mater., 2007, 6, 183. 55 C. N. R. Rao, K. Biswas, K. S. Subrahmanyam and A. Govindaraj, J. Mater. Chem., 2009, 19, 2457.

56 K. S. Novoselov, A. K. Geim, S. V. Morozov, D. Jiang, Y. Zhang, S. V. Dubonos, I. V. Grigorieva and A. A. Firsov, Science, 2004, 306, 666.

57 A. V. Murugan, T. Muraliganth and A. Manthiram, Chem. Mater., 2009, 21, 5004. 
58 Z. S. Wu, W. C. Ren, D. W. Wang, F. Li, B. L. Liu and H. M. Cheng, Am. Chem. Soc. Nano, 2010, 4, 5835.

59 K. S. Novoselov, A. K. Geim, S. V. Morozov, D. Jiang, M. I. Katsnelson, I. V. Grigorieva, S. V. Dubonos and A. A. Firsov, Nature, 2005, 438, 197.

60 B. Seger and P. V. Kamat, J. Phys. Chem. C, 2009, 113, 7790. 61 S. Stankovich, D. A. Dikin, G. H. B. Dommett, K. M. Kohlhaas, E. J. Zimney, E. A. Stach, R. D. Piner, S. T. Nguyen and R. S. Ruoff, Nature, 2006, 442, 282.

62 J. W. Zhu, G. Y. Zeng, F. D. Nie, X. M. Xu, S. Chen, Q. F. Han and X. Wang, Nanoscale, 2010, 2, 988.

63 R. Pasricha, S. Gupta and A. K. Srivastav, Small, 2009, 5, 2253.

64 J. Dong, W. Liu, H. Li, X. Su, X. Tang and C. Uher, J. Mater. Chem. A, 2013, 1, 12503.

65 H. Chen, C. Yang, H. Liu, G. Zhang, D. Wan and F. Huang, CrystEngComm, 2013, 15, 6648.

66 B. Liang, Z. Song, M. Wang, L. Wang and W. Jiang, J. Nanomater., 2013, 2013, 5.

67 L. Wang, F. Liu, C. Jin, T. Zhang and Q. Yin, RSC Adv., 2014, 4, 46187-46193.

68 B. Feng, J. Xie, G. Cao, T. Zhu and X. B. Zhao, J. Mater. Chem. A, 2013, 1, 13111-13119.

69 G. A. Slack, in CRC Handbook of Thermoelectrics, CRC, New York, 1995.

70 S. M. Kauzlarich, Chemistry, Structure, and Bonding of Zintl Phases and Ions, VCH Publishers, New York, 1996.

71 S. M. Kauzlarich, S. R. Brown and G. J. Snyder, Dalton Trans., 2007, 2099.

72 A. M. Mills, R. Lam, M. J. Ferguson, L. Deakin and A. Mar, Coord. Chem. Rev., 2002, 233, 207.

73 G. A. Slack, Solid State Phys., Academic Press, New York, 1979.

74 E. S. Toberer, A. Zevalkink and G. J. Snyder, J. Mater. Chem., 2011, 21, 15843.

75 M. M. Ripoll, A. Haase and G. Brauer, Acta Crystallogr., 1974, B30, 2006.
76 J. H. Slowik, Phys. Rev. B: Solid State, 1974, 10, 416.

77 L. M. Watson, C. A. W. Marshall and C. P. Cardoso, J. Phys. F: Met. Phys., 1984, 14, 113.

78 C. Zheng, R. Hoffmann, R. Nesper and H. G. von Schnering, J. Am. Chem. Soc., 1986, 108, 1876.

79 S. R. Dhakate, S. Sharma, M. Borah, R. B. Mathur and T. L. Dhami, Int. J. Hydrogen Energy, 2008, 33, 7146.

80 T. Gupta, B. P. Singh, R. B. Mathur and S. R. Dhakate, Nanoscale, 2014, 6, 842.

81 M. Borah, M. Dahiya, S. Sharma, R. B. Mathur and S. R. Dhakate, Mater. Focus, 2014, 3, 300-309.

82 F. Schedin, A. K. Geim, S. V. Morozov, E. W. Hill, P. Blake, M. I. Katsnelson and K. S. Novoselov, Nat. Mater., 2007, 6, 652.

83 Z. J. Fan, W. Kai, J. Yan, T. Wei, L.-J. Zhi, J. Feng, Y.-M. Ren, L. P. Song and F. Wei, ACS Nano, 2011, 5, 191.

$84 \mathrm{~J}$. Zhou, H. Song, L. Ma and X. Chen, RSC Adv., 2011, 1, 782. 85 V. G. Kravets, R. Jalil, Y.-J. Kim, D. Ansell, D. E. Aznakayeva, B. Thackray, L. Britnel, F. Withers, I. P. Radko, Z. Han, S. I. Bozhevolnyi, K. S. Novoselov, A. K. Geim, B. D. Belle and A. N. Grigorenko, Sci. Rep., 2014, 4, 4237.

86 M. J. Webb, P. Palmgren, P. Pal, O. Karis and H. Grennberg, Carbon, 2011, 49, 3242.

87 C. H. A. Wong and M. Pumera, J. Mater. Chem. C, 2014, 2, 856.

88 M.-C. Hsiao, S.-H. Liao, M.-Y. Yen, C.-C. Teng, S.-H. Lee, N.-W. Pu, C.-A. Wang, Y. Sung, M.-D. Ger, C.-C. M. Ma and M.-H. Hsiao, J. Mater. Chem., 2010, 20, 8496.

89 V. Johnson and K. Lark-Horovitz, Phys. Rev., 1953, 92, 226.

90 A. Bhardwaj and D. K. Misra, J. Mater. Chem. A, 2014, 2, 20980-20989.

91 H. Kitagawa, M. Wakatsuki, H. Nagaoka, H. Noguchi, Y. Isoda, K. Hasezaki and Y. J. Noda, Phys. Chem. Solids, 2005, 66, 1635.

92 W. S. Liu, B. P. Zhang, J. J. F. Li, H. L. Zhang and L. D. Zhao, J. Appl. Phys., 2007, 102, 103717. 